\title{
La restauración de la Orden Franciscana en España: La Provincia Bética Franciscana (1881-1888)
}

\author{
The restoration of the Franciscan Order in Spain: \\ The Betica Franciscan Province (1881-1888)
}

\author{
Manuel Villena Villar \\ Graduado en Historia por la Universidad de Sevilla (2019), Máster en Estudios \\ Históricos Avanzados en la Universidad de Sevilla (2020) \\ https://orcid.org/0000-0002-0226-8516
}

\begin{abstract}
Resumen: la llegada de Alfonso XII y la expulsión de los religiosos de Francia provocaron la conjunción perfecta para que el franciscanismo sevillano se revitalizara y restableciera. En el presente trabajo presentamos un acercamiento a la restauración del franciscanismo en la diócesis de Sevilla de la mano de la observancia francesa, expulsada de Francia, y que entroncará con la antigua Provincia Bética Franciscana.
\end{abstract}

Palabras clave: franciscanos; restauración borbónica; órdenes religiosas; Sevilla; exilio.

\begin{abstract}
The arrival of Alfonso XII and the expulsion of the religious from France brought about the perfect conjunction for the revitalisation and re-establishment of Sevillian Franciscanism. In this work we present an approach to the restoration of Franciscanism in the diocese of Seville by the French observance, expelled from France, and which will be linked to the old Betica Franciscan Province.
\end{abstract}

Keywords: franciscains; bourbon restoration, religious orders; Seville; exile.

En el famoso Manifiesto de Shandurst (1874), Alfonso XII afirmaba que ni dejaré de ser buen español, ni como todos mis antepasados, buen católico, ni, como hombre de siglo, verdaderamente liberal. De esta forma expuso las bases del sistema que Cánovas del Castillo tenía ideado: la unión, la alternancia, la estabilidad y la permanencia de un modelo que diera solidez al país. El Estado se encontraba inmerso en el último conflicto carlista, con fuertes movimientos secesionistas, teniendo su culmen en la sublevación cantonal, mientras que la economía nacional seguía lastrada y los últimos territorios de ultramar se preparaban para los intentos de separación de España. El nuevo 
proyecto nacional de estabilidad se materializó el 14 de enero de 1875 con la entrada triunfal de Alfonso XII en Madrid, dando por terminada la etapa revolucionaria y la primera experiencia republicana de la nación española ${ }^{1}$.

\section{LAS ÓRDENES RELIGIOSAS EN EL CANOVISMO}

Con el fin de las aventuras políticas se hizo latente que la restauración sistemática de las órdenes religiosas en nuestro suelo no tardaría en llegar, aprovechando los nuevos vientos políticos, sociales, intelectuales y eclesiales, donde los religiosos comenzaron a volver a sus claustros y ejercer las misiones propias de los institutos religiosos a los que pertenecían. Las órdenes religiosas que se fueron asentando en el territorio español podían mantenerse encubiertas gracias a la nueva política estatal, amparada en el antiguo Concordato y a la inscripción de éstas en el registro de asociaciones civiles²

Para la Iglesia, la vuelta de la monarquía supuso una entrada de aire fresco en una habitación cuyo ambiente se hallaba viciado. Este sentimiento fue compartido por los delegados romanos, que en mayo de 1874 informaron a Roma de manera principalmente positiva sobre el nuevo modelo: estaba compuesto por elementos que habian contribuido con el general Pavía al golpe ${ }^{3}$ que precipitó el regreso de la monarquía. Unas impresiones confirmadas aún más si nos atenemos a la Circular del 2 de enero de 1875, en la que el nuevo monarca se presentaba ante la Iglesia en los siguientes términos:

Constituido el Ministerio-Regencia he creído de mi deber dar conocimiento oficial a $V \ldots$ del fausto acontecimientos a que debe su origen. En las relaciones de los Estados católicos con la Iglesia, lo que para aquellos en próspero suceso, para esta no puede menos ser feliz augurio de bienandanza. Si la Iglesia ha padecido con la Nación española los males sin cuento de estériles trastornos políticos, con el advenimiento al Trono de un ilustre Príncipe, católico como sus preclaros antecesores y decidido a reparar en

1 José Luís ABELLÁN GARCÍA-GONZÁLEZ: Historia crítica del pensamiento español. La crisis contemporánea (1875-1936), tomo 5-1, Madrid, Espasa-Calpe, 1989, p.15.

2 José GARCÍA ORO: Los franciscanos en España. Historia de un itinerario religioso, A Coruña, Editorial El Eco Franciscano, 2006. p. 281.

3 Vicente CÁRCEL ORTÍ: Iglesia y revolución en España (1868-1874), Pamplona, Ed. Universidad de Navarra, 1979, p. 335. 
cuanto sea posible los daños causados, debe esperar días bonancibles y de mayor ventura. La proclamación de nuestro Rey D. Alfonso XII, siendo el verdadero término de aquellos disturbios, será por lo mismo el principio de una nueva era, en la cual se verán restablecidas nuestras buenas relaciones con el Padre común de los fieles, desgraciadamente interrumpidas por las injusticias y los excesos de estos últimos tiempos; se procederá en todo lo que pueda afectar a estas recíprocas relaciones con el consejo de sabios Prelados y de acuerdo con la Santa Sede; y se dará a la Iglesia y sus Ministros toda la protección que se les debe en una Nación como la nuestra eminentemente católica. Para ellos cuenta el Gobierno con la eficaz cooperación de V... y de sus dignos compañeros del Episcopado; con la ayuda de las altas corporaciones del Estado, y con el auxilio de los buenos católicos; me complazco en transmitir a $V$... la nueva feliz de esta saludable mudanza en nuestra situación política que nos permite esperar días más dichosos para la Nación, y época de más ventura para la Iglesia4.

Esta idea inicial, que podemos prever como la vuelta a la situación privilegiada de la Iglesia tras el Concordato de 1851, no fue posible. Cánovas intuyó que tras los procesos revolucionarios tal realidad no era tan factible ya que, si bien los proyectos del Sexenio se quedaron en utopía, también hubo algunos que se materializaron en parte. En este sentido se articuló la Constitución de 1876, que respetaba el principio de libertad religiosa, pese a las enérgicas quejas de Pío IX y del episcopado ${ }^{5}$. Pronto parecía que el nuevo rey no podría hacer realidad sus intenciones. A pesar de ello, en la nueva Constitución se recogió que:

[...] la religión católica, apostólica, romana, es la del Estado. La Nación se obliga a mantener el culto y sus ministros. Nadie será molestado en el territorio español por sus opiniones religiosas ni por el ejercicio de su respectivo culto, salvo el respeto debido a la moral cristiana. No se permitirán, sin embargo, otras ceremonias públicas que las de las de la religión del Estado.

Esta regulación conllevaba armonía, aunque forzada, entre fuerzas políticas abocadas al entendimiento, donde finalmente la Iglesia también se involucró. De esta manera, si la Iglesia del inicio de la

4 Circular 2-I-1875 del Ministro de Gracia y Justicia a todos los Prelados de la Iglesia Católica en nuestra nación.

5 Roger AUBERT: La iglesia entre la revolución y la restauración en Hubert JEDIN (ed.): Manual de Historia de la Iglesia, vol.VII, Barcelona, Ed. Herder, 1978, p. 895.

6 Constitución Española de 1876. Art. 11.30-VI-1876. 
Restauración encaró con recelo, aunque con esperanza velada, el nuevo modelo político, pronto se daría cuenta de la necesidad de unión y legitimación de la nueva realidad. Así, entre 1876 y 1885, se da un giro y se pasa del recelo a la solidaridad y al apoyo mutuo frente a la amenaza republicana y socialista que aparece en los años ochenta ${ }^{7}$. García de Cortázar hablaba de un pacto de la Iglesia con la burguesía española, donde la primera había representado uno de los últimos pilares del Antiguo Régimen mientras que ahora bendecía las riquezas de los burgueses, amasadas en el trasiego de la propiedad desamortizada ${ }^{8}$. En el mismo sentido nos dice A. Moliner Prada que la Iglesia se dirigió entonces a la cristianización de las élites de la sociedad, el acatamiento de los poderes civiles y el combate de la legislación anticristiana por los medios legales $^{9}$. Para Alfonso Botti esta nueva forma de establecer la política se entiende cómo una defensa de los intereses de la Iglesia a través de la recomposición de la unidad de los católicos al margen [...] del Carlismo y su influencia en el Estado a través de la confluencia en el partido liberal conservador de Cánovas ${ }^{10}$. Y es que, la institución partía, ya desde los debates al texto constitucional, del discurso que identificaba el ser de España con la unidad bajo el catolicismo (con argumentos parecidos a los usados en el Sexenio para evitar la libertad de cultos), de ahí su férrea resistencia a la continuación de tolerancia religiosa con veladas amenazas: el prescindir de la unidad católica es renunciar a la estabilidad politica, porque implica olvidar ${ }^{11}$.

La Iglesia se vio forzada a olvidar el pasado impulsada por León XIII (1878-1903), este nuevo papa conminó a la jerarquía eclesiástica española a aceptar los postulados liberales y a acomodarlos desde la perspectiva eclesial. Esta idea suponía dejar atrás a los católicos identificados con la bandera carlista y el integrismo, atados a una tradición que la Iglesia quería alejar de ella y bastante disonante en la

7 Cristóbal ROBLES MUÑOZ: Insurrección o legalidad: los católicos y la restauración, Madrid, CSIC, 1989, p. 241.

8 Fernando GARCÍA DE CORTÁZAR: Iglesia y sociedad en la España contemporánea, en "Estudios sobre Historia de España (vol. II)", Madrid, UIMP, p, 567.

9 Antonio MOLINERY PRADA: Clericalismo y anticlericalismo en la España contemporánea,"Historia. Questôes \& Debates", 55 (2011), pp. 59-82., p. 68.

10 Alfonso BOTTI: Cielo y dinero, Madrid, Alianza Editorial, 2008. p. 73.

11 José A. TELLO LAZARO: La Iglesia en el proceso constitucional de la Restauración (cap. III), en "Anales de la Fundación Joaquín Costa", 2 (1985), p. 36. 
nueva época que se abría ${ }^{12}$. La crismación por parte del papa de esta nueva posición vino de la mano de la encíclica Inmortale Dei en la que se declaraba que si bien la política debe basarse sobre la religión [...], la religión y la política son, sin embargo, cosas muy distintas y que jamás deben confundirse ${ }^{13}$, una petición a los católicos que contrastaba con la tenida por el catolicismo español solo unos años antes: católicos antes que políticos; políticos en tanto cuanto la política conduzca al triunfo práctico del catolicismo ${ }^{14}$. Esta nueva legitimación, desde y hacia la Iglesia, le brindó un amplio reconocimiento social y político, a la par que le volvía a abrir las puertas a alcanzar las cuotas de poder, pérdidas a lo largo de los procesos revolucionarios de la España de mediados del siglo XIX. Un dato nos permite tomar conciencia de tal afirmación: en 1859, había en España cuarenta y ocho mil ochocientos cinco religiosos, mientras que en 1910, nos encontramos con un aumento que lleva la cifra hasta los ochenta y ocho mil setecientos veintiuno ${ }^{15}$.

Estos movimientos, unidos a la llegada al poder de los liberales conservadores, consiguieron que la Iglesia lograra sacar del escenario fáctico de la política a los anticlericales del Sexenio, provocando una migración en el discurso en contra de la Iglesia. Si en buena parte del siglo XIX predominó un ataque carente de base intelectual sólida, violento e incendiario hacía la Iglesia ${ }^{16}$; ahora nos encontramos con el predominio del anticlericalismo intelectual, que usa la prensa y la propaganda para lograr sus objetivos en tanto han sido discriminados de la representación en el nuevo sistema ${ }^{17}$. Es un paso más en la nueva situación de la Iglesia y, con ella de los regulares, donde, si bien serán criticados cuando comiencen a instalarse, no mantendrán

12 Santiago PETSCHEN VERDAGUER: España y el Vaticano: del Concordato de 1851 al de 1953, en "Religión y sociedad en España (siglos XIX y XX)", Madrid, Casa Velázquez, 2002, pp. 21-32.p. 31.

13 Vicente CARCEL ORTI: San Pío X y la primera asamblea del episcopado en 1907, en "Archivum Historiae Pontificiae", 30 (1997), p. 310.

14 Lema bajo la cabecera que aparece en el periódico La Regeneración en el año 1860.

15 Juan Pablo FUSI y Jordi PALAFOX: España: el desafío de la modernidad (18081996), Madrid, Espasa, 1997, p. 156.

16 Ibid..., p. 66.

17 Jorge VILCHES GARCÍA: El posibilismo español republicano ante el catolicismo durante el reinado de Alfonso XII. A propósito de los sucesos de Santa Isabel, en "Hispania", 241 (2012), p. 539. 
en sus corazones el temor a un rebrote inminente de anticlericalismo como el de los años treinta o del cercano Sexenio.

A pesar de toda la nueva legislación y la tolerancia del gobierno, el reinado de Alfonso de XII no fue tan duradero como para lograr fijar el sistema de la Restauración. Este modelo constituyó el sostén de la restauración de las órdenes religiosas, por lo que debemos entender que la Iglesia fue una fuerte promotora de la estabilización. En tal caso debemos hablar de Iglesia en su conjunto ya que, como es lógico, las órdenes religiosas también deseaban el asentamiento del sistema pero su poder fáctico para poder proveer a ello se veía limitado por la desorganización interna y el verse ocupadas de lleno en los procesos restauracionistas. Sin embargo, no supuso inconveniente para que muchas de las órdenes ya instaladas comenzaran actividades propias de cada una, amparadas en la protección de los prelados diocesanos, sus representantes ante el gobierno desde la exclaustración, que veían la necesidad de aumentar la piedad popular mediante misiones y ejercicios espirituales ${ }^{18}$.

$\mathrm{Al}$ margen de sujetos eclesiales hay que considerar que tal sistema se fijó, en gran parte en 1878, con la Ley Electoral asentada en el sistema censitario, consolidando el poder electoral de la burguesía, mientras que el Turno Pacífico lo proveyó de estabilidad. La continuidad era simple: un sistema corrupto, con caciques como delegados locales que amañaban los procesos electorales, propiciando la alternancia en el poder de conservadores y liberales. Estos planteamientos fueron fijados por Cánovas y Sagasta, a la sazón los líderes de los partidos conservador y liberal, en el conocido como Pacto del Pardo (1885), un pacto que estará presente todo el período de la regencia de María Cristina (1885-1890), por lo que el objeto del presente trabajo se enmarca dentro de mencionado proceso político.

La Restauración no conllevó un tiempo de unión trono-altar, tal y como había ocurrido en períodos anteriores, sino que la Iglesia consciente de los cambios de la sociedad y las nuevas armas puestas en juego, destacando el, cada vez más notable, protagonismo de la prensa, volvió a hacer un uso de las letras como arma. Se hacían necesarias justificaciones teóricas que hicieran frente a los ataques de los anticlericales, que habían quedado en su mayoría reducidos a la acción intelectual debido a dos motivos: la prensa era un excelente

18 José GARCÍA ORO: Los franciscanos en España. Historia, 282. 
medio de propaganda, y los ataques violentos serían duramente reprimidos por un gobierno cuyo afán principal era la estabilidad. La Iglesia articuló la nueva defensa convencida de situarse como el único camino de salvación, en contraposición a todos los fenómenos que estaban teniendo lugar. Uno de los argumentos más reiterados fue presentar a la Iglesia como salvadora del alma española de la apostasía, mientras que la vida religiosa -de los regulares- fue mostrada como el espejo al que mirar para aquel que quisiera salvarse ${ }^{19}$.

Desde la Orden Franciscana, el nuevo modelo político español era visto como una tregua de la intolerancia. Para el comisario apostólico, los laudables esfuerzos de algunos provinciales que, con la mayor pena, veían extinguirse la vida franciscana en España contribuyeron a restaurar la Orden en España ya que, antes de 1880, ya se habían establecido conventos en varios puntos de la península (Cantabria, Murcia, Cataluña) mientras que otros territorios eran verdaderos desiertos de franciscanismo. Estos páramos se vieron acentuados con la falta de peticiones de instalación de comunidades al gobierno, poniendo de relieve carencias de liderazgo en los exclaustrados que aún quedaban vivos y podían servir como punto de unión de sus antiguos hermanos de religión. A este panorama, se unió la dispersión de los religiosos que conllevó a que las diferencias entre ramas franciscanas se vieran casi anuladas, elemento que actuará de manera positiva en tiempos venideros cuando el papado unifique a la familia franciscana.

Riquelme Oliva nos presenta una serie de factores proclives a la restauración de las órdenes religiosas: una política favorable por parte del gobierno asentada en la atracción del elemento católico al nuevo sistema político, el pensamiento de la generación de Donoso y Cortés que alimenta las esperanzas de refundación y un fervor religioso recuperado, que llenó los noviciados de las órdenes ${ }^{20}$.

Si en nuestro país la restauración de la monarquía conllevó el regreso de las órdenes religiosas, no ocurría lo mismo en Francia donde el clero regular fue expulsado en 1880. Parte de los religiosos se asentaron en España dando lugar al comienzo de la refundación de los conventos abandonados desde los procesos desamortizadores de los años treinta. En los siguientes apartados exponemos y analizamos

19 Frances LANNON: Privilegio, persecución y profecía. La Iglesia Católica en España en 1875-1975, Madrid, Alianza Editorial, 1990, p. 86.

20 Pedro RIQUELME OLIVA: Restauración de la Orden Franciscana en España. La provincia franciscana de Cartagena (1835-1878), Murcia, ITM, 2000, p. 329. 
las consecuencias que dichos movimientos provocaron en los franciscanos menores de la archidiócesis de Sevilla. Esta cuestión ya se ha venido tratando dentro de la familia franciscana desde los años iniciales de la restauración de la provincia en escritos como el Estudio sobre la restauración de la Provincia Bética del P. Mariano de San José; Historia de la imagen y santuario de Loreto (1906) y Las Casas de Estudio de la Provincia de Andalucía (1917) de fray Ángel Ortega; Los Estudios en la Provincia Bética (1956) de fray Marcelino Barrado Manzano; La provincia Bética de la Orden de los Frailes Menores de fray Sebastián García Garrido (1999); y Los franciscanos en Sevilla (2008) de fray Luís García Chávez.

\section{LAS ÓRDENES RELIGIOSAS EN LA III REPÚBLICA FRANCESA}

En el país galo, la dinámica política de la III República (1870-1940) y la llegada al poder de unas izquierdas con un potente sector anticlerical supusieron el advenimiento de toda una legislación anti eclesiástica, provocando la expulsión de la mayoría de los religiosos del suelo francés. En mayo de 1877, el republicano León Gambetta (1838-1882) expuso en el parlamento francés uno de los objetivos del nuevo sistema: eliminar el clericalismo, jeste es el enemigo! ${ }^{21}$. La sustentación teórica de esta política contra el clero se enmarcaba en lo que A. Mira Abad y M. Moreno Seco han denominado como "vicios tópicos" 22 . La citada tipología de anticlericalismo ha sido analizada en los discursos en torno al clero alicantino, de aplicación a todos los discursos anticlericales. Estos tópicos se pueden resumir en que el clero constituye un sector peligroso para las instituciones políticas debido a que el sacramento de la confesión provocaba grandes fisuras en los hogares, siendo vistos los votos religiosos como anti naturales, considerándolos como enemigos de lo moderno, con la calificación de inútiles para la sociedad, partidarios de formas de gobierno reaccionarias obstaculizadoras de la modernización... y un largo sin fin en el mismo sentido que solo hacían alimentar la maquinaria anticlerical.

21 Jacqueline LALOUETTE: El anticlericalismo en Francia, "Ayer", 27 (1997), p. 16.

22 Alicia MIRA ABAD y Mónica MORENO SECO: Alicante en el cambio del siglo XIX al XX: secularización y modernidad, en"Hispania Nova", 3 (2003), http://hispanianova.rediris.es/articulos/03_007.htm. (Consultado el 28-III-2020). 
En el supuesto francés, estos ataques también debían buscar justificaciones tangibles para una futura expulsión de los religiosos, por lo que el gobierno galo encargó en 1877 que parte del presupuesto fuese destinado a investigar la importancia de las órdenes religiosas en el país. Se temía el gran influjo que la Iglesia tenía a través de sus instituciones educativas, caritativas, parroquias e iniciativas laicas ${ }^{23}$. Esta influencia reflejaba la misma situación que en España. El clero regular se hacía necesario para suplir las faltas de un Estado que, aún en formación, no podía ocupar él mismo. Tollo ello explica que en el Concordato con España (1851) se permitiera la existencia de órdenes destinadas a la caridad, lo mismo que en el Sexenio (1868-1874). Esta razón no fue suficiente para el gobierno francés que, en 1878, con la celebración del centenario de Voltaire, orquestó una gran ofensiva anti católica que se plasmó en la campaña electoral de dicho año. En las elecciones triunfaron las tesis anticlericales más exacerbadas que tenían el objetivo claro de eliminar la enseñanza religiosa y las congregaciones. Junto al clericalismo se esgrimió otro tipo de planteamiento que presentaba a los católicos franceses, muy divididos, como enemigos de la República, a pesar de que ciertos obispos y religiosos declaraban abiertamente que la sociedad francesa era democrática y republicana ${ }^{24}$.

Las aspiraciones contra el clero se vieron colmadas con el republicano de izquierdas Jules Ferry (1832-1893), ministro de Instrucción Pública, que, en 1879, apoyándose en la no existencia de autorizaciones en la mayoría de congregaciones para que pudieran impartir la enseñanza, comenzó a aplicar los decretos. En virtud del artículo 7 de su proyecto de ley se prohíbe lo dicho, estableciendo una serie de decretos y comenzando las expulsiones con los hermanos de la Compañía de Jesús ${ }^{25}$. Hay que destacar de estos decretos que, publicados el 29 de marzo, pedían a toda comunidad no autorizada que obtuviera una autorización legal para seguir como tal, que sus decretos y constituciones fueran aprobadas por el gobierno para que cada una de las casas abiertas por las instituciones fueran reconocidas

23 Jacques GADILLE: Fracaso de la reconciliación en Francia, en Hubert JEDIN (ed.): Manual de Historia de la Iglesia, vol.VII, Barcelona, Ed. Herder, 1978, p. 162.

24 Bernardino LLORCA, Ricardo GARCÍA-VILLOSLADA, y José María LABOA: Historia de la Iglesia Católica V: Edad Contemporánea, Madrid, BAC, 1999, p. 352.

25 Jacques GADILLE: “Fracaso de la reconciliación en Francia”, en Hubert JEDIN (ed.): Manual de Historia de la Iglesia, vol.VII, Barcelona, Ed. Herder, 1978, p. 163. 
como legales. El plazo para la legalización era de tres meses, por lo que la eficacia de los mismos para justificar la expulsión era muy alta, ya que las órdenes debían realizar un gran esfuerzo burocrático en un tiempo limitado. El gobierno no hizo ningún tipo de permuta, provocando que en mayo comenzaran las expulsiones de órdenes religiosas. Gran parte de la sociedad gala no vio estos ataques como un atentado sino que entendían que la defensa de la República primaba sobre los intereses personales, pensamiento que se justificaba con que la mayoría de los líderes católicos laicos estaban ligados a movimientos pro monárquicos ${ }^{26}$.

El primer exilio (puesto que entre 1901 y 1906 se da un segundo exilio) provocó que nuestro país fuera un referente cercano para la acogida: la cercanía geográfica, el ser puente para los territorios ultramarinos y la vuelta de la monarquía con Alfonso XII, con una relajación en el discurso en torno al clero, sirvieron de punto de atracción. El gobierno galo obtuvo del español la promesa de que los frailes, considerados como sediciosos no se establecerían en las fronteras limítrofes (Navarra, Lérida, Huesca, Guipúzcoa y Gerona). Unas restricciones que no fueron tan reales como puede parecer ${ }^{27}$. El total de religiosos expulsados es diferente en atención a las fuentes, siendo la cifra más realista la que suministra Pedro Dávila (2011) con mil religiosos exiliados. Entraron en territorio español un total de dieciséis congregaciones, de las que trece eran femeninas y tres masculinas, algunas estableciéndose por primera vez y otras aumentando el número de las que llegaron con los procesos de la Revolución Francesa ${ }^{28}$.

\section{LA EXPULSIÓN DE LOS FRANCISCANOS DE FRANCIA Y SU LLEGADA A ESPAÑA}

La vuelta de la Orden de Frailes Menores a Sevilla no tuvo lugar con los frailes españoles sino que fueron los religiosos franceses expulsados los que llegaron al sur peninsular buscando un lugar donde

26 Bernardino LLORCA, Ricardo GARCÍA-VILLOSLADA, y José María LABOA: Historia de la Iglesia..., 353.

27 Como veremos más adelante el gobierno español negaba el asentamiento de religiosos mientras que, sin publicarlos en La Gaceta, daba permiso para dicho establecimiento.

28 Pedro BALSERA DÁVILA: Las órdenes y congregaciones religiosas francesas y su impacto sobre la educación en España: siglos XIX y XX, Salamanca, USAL, 2011, p. 120. 


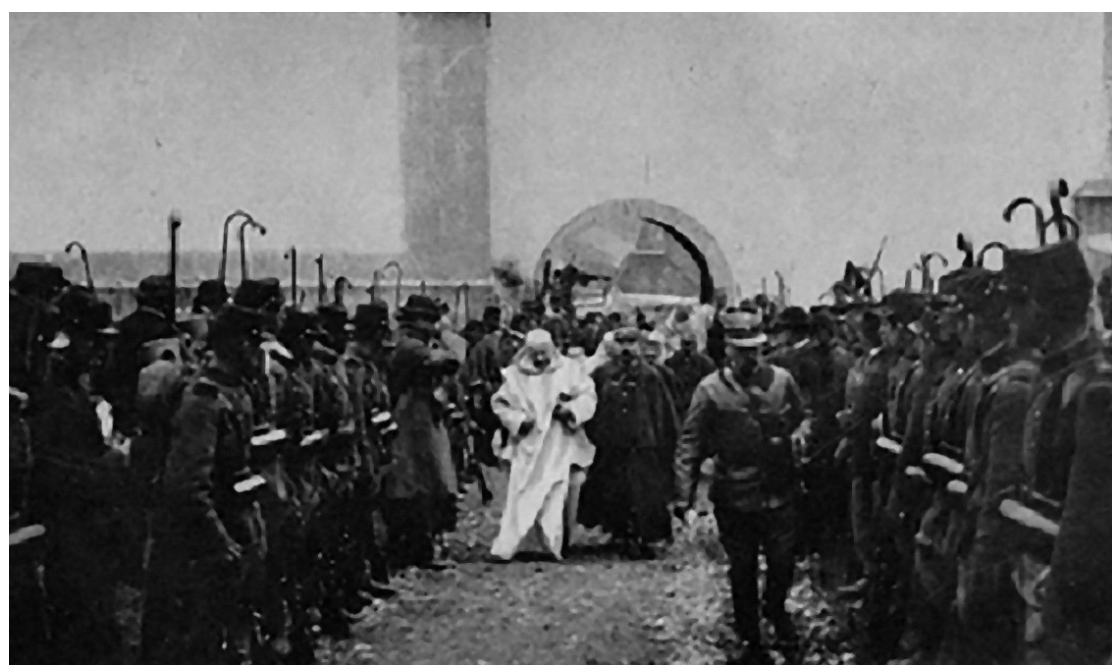

Expulsión de los monjes de la Gran Cartuja (Francia) en la ola anticlerical de 1904.

alojar a sus estudiantes y novicios, un hecho que parece único en el franciscanismo español. Como veremos en este apartado la llegada de los frailes, su instalación y vida en Sevilla no resultó sencilla sino que más bien se trató de un "pequeño exilio" que acabaría antes de lo que ellos tenían pensado, pero dejando la semilla de la refundación de la antigua provincia franciscana observante de Andalucía

\subsection{La provincia franciscana de San Louis de Anjou}

La provincia franciscana francesa de San Louis de Anjou fue erigida el 20 de octubre de 1860, encarnando el restablecimiento oficial de los franciscanos tras las revolución de 1789. La refundación tuvo lugar gracias al apoyo de exclaustrados españoles, destacando al franciscano observante navarro fray José Areso que se unió a otros exclaustrados y que, junto a los frailes franceses, iniciaron una intensa labor por restablecer el franciscanismo observante en Francia. Tal fama adquirió el navarro que el ministro general de la observancia le encargó el restablecimiento de la vida religiosa franciscana en el país en el año $1849^{29}$. En el territorio que abarcaba su jurisdicción se fundaron los conventos de Saint-Palais, Amiens, Limoges, Branday y Bourges. Este último va a guardar en nuestro análisis una significación especial por varios motivos: la calidad

$29 \quad$ Ibid..., 1. 
del convento como colegio de misiones llevó a que muchos jóvenes españoles que deseaban ser religiosos misioneros fueron educados alli ${ }^{30}$, jóvenes en su mayoría de las provincias limítrofes con Francia, y además, siendo la comunidad que acabaría mayoritariamente asentada en el convento de Loreto (Espartinas, Sevilla).

La política del nuevo gobierno nacional conllevó que la provincia franciscana de San Louis de Anjou abordara en sus reuniones definitoriales ${ }^{31}$ esa nueva realidad y reflexionó sobre cuál sería el destino más seguro para los hermanos cuando llegara el momento de la expulsión. Los franciscanos estaban a la expectativa ya que miembros de otras órdenes se internaron en nuestro territorio de forma desorganizada, tal y como se observa en la prensa del momento ${ }^{32}$; mientras que otros, aun con el recuerdo de los resultados de una expulsión desorganizada, esperaban órdenes de los superiores. Desorganizada u organizada, la llegada de esos religiosos a nuestro país provocó un recrudecimiento de efervescencia contras las órdenes religiosas ${ }^{33}$.

El definitorio de la provincia de Saint Louis se reunió para tratar los pasos a seguir con la ejecución de los decretos del 29 de marzo ${ }^{34}$. Una de las opciones más viable consistía en ir a Cantabria donde serían recibidos en los conventos de Soto y Castro, que creían idóneos para los novicios, a la par que contemplaban alquilar el convento de Santo Tomás (Vich). En una reunión posterior decidieron a pasar también religiosos a Inglaterra. Del mismo modo se elaboró un protocolo a seguir en cada comunidad: lo primero que debían hacer los frailes cuando las autoridades los expulsaban del convento era remitir un telecable al padre provincial indicándole la fecha y hora de

30 Hugues DEDIEU: Flashes sur l'historie de la Province..., 11.

31 "Asamblea o junta compuesta por los religiosos definidores de las órdenes religiosas y presidida por el provincial o general, según su jurisdicción, que atiende a las cuestiones de gobierno no tratadas en los capítulos"en Enrique MARTINEZ RUIZ (coord.): Diccionario de Historia Moderna de España. La Iglesia, Madrid, Ed. Istmo, 1998, p. 108.

32 Un ejemplo de ello lo encontramos en el diario republicano posibilista El Graduador (Alicante) que durante todo 1880 va recogiendo las noticias de la llegada de los religiosos con un claro matiz anticlerical. El día 19 de mayo de 1880 publicaban:"Puede ya asegurarse que el gobierno austríaco ha tomado la resolución de no admitir en el territorio de aquel imperio a los jesuitas expulsados de Francia. Ni aún allí, donde el espíritu de la teocracia predomina, quieren a esa gente. ¿Será buena?".

33 José ANDRÉS GALLEGO: La política religiosa en España, 267.

34 Hugues DEDIEU: Flashes sur l'historie de la Province..., 14. 
la expulsión, sin perjuicio de que días posteriores le remitieran una carta explicándole el desarrollo de los acontecimientos.

En el convento de Burdeos nos encontramos con el testimonio del padre Jean-Joseph Fabre, de noviembre de 1880, que insertamos a continuación, advirtiendo que son textos internos de la Orden que nos permiten observar la situación de estos frailes en el transcurso de los acontecimientos:

Burdeos, 8 de noviembre de 1880

Mi muy reverendo Padre

Como ya le dije por telégrafo, hemos sido expulsados esta mañana a las seis y media de la mañana. La puerta exterior del edificio ha sido derribada con un hacha, y ha sido a través de ella como los agentes han penetrado en el convento. Hemos protestado contra la violación del domicilio y declaramos que solo saldríamos por la fuerza. Quería leer una protesta escrita que se negaron a escuchar. Los agentes comenzaron a buscar a los religiosos, también a los enfermos, que estaban en sus celdas y fueron conducidos a la puerta. Las puertas fueron forzadas con golpes de hachas. Incluso la puerta de la sacristía fue golpeada con el hacha para abrirla, a pesar de que la llave estaba en la misma puerta. Era sombrío escuchar los golpes de hacha por los pasillos, derribando las puertas, un trabajo que duró al menos una hora. Hubo muchos testigos en la casa. Los religiosos enfermos estaban encerrados en sus celdas, los guardias los buscaron y los condujeron a la puerta. Los hermanos golpeaban las puertas exteriores y la campana durante todo el tiempo, lo que enfadaba a los agentes y ordenaron que cesara todos esos ruidos. Con una sirena indescriptible, el comisario, los gendarmes y una docena de trabajadores estaban preparados con las hachas y con barras de hierro. Toda esta gente entró por la puerta principal al jardín, y desde ahí a la cocina. Fue delate de la puerta de la cocina donde el comisario de la prefectura me ha arrestado, mientras todos mis miembros temblaban. María de Urdon estaba cerca de mí, y me encontré en la casa con el hermano Silvano y el hermano Yves. Todos fueron expulsados y la puerta de la capilla cerrada. He cogido al Santo Sacramento del sagrario y lo he llevado a una celda. María de Urdon ha intentado llegar a casa del alcalde. Los estudiantes se atrincheraron y pusieron obstáculos en las escaleras, por lo que a los agentes les costó mucho subir ya que la otra escalera, hecha dentro de la comunidad, no la encontraron. Estuvieron mucho tiempo en la escalera por lo que al final rompieron los cristales para entrar [...] Todos los religiosos fuimos bienvenidos y acogidos en casas ${ }^{35}$.

35 Lettres et télégrammes rédigés au moment des expulsions de 1880 concernant, Bourges (4-XI-1880), AHPFP (Archivo Histórico de la Provincia Franciscana de París), Expulsion 1880. El original en francés. 
La acogida de los religiosos expulsados de los conventos se venía gestando desde antes, ya que, según se desprende de la documentación ${ }^{36}$, el padre provincial recibió ofrecimientos por parte de monasterios de clarisas, curas párrocos y seglares. No fue una expulsión por sorpresa, sino que, como hemos indicado, el gobierno francés fue aprobando decretos mientras que el de la provincia también iba tomando iniciativas para paliar los efectos de los mismos, o, al menos, para evitar la dispersión de los hermanos y la posterior, como había ocurrido con anterioridad, imposible comunicación teniendo la extinción de la provincia en consecuencia. Parte de estos religiosos habían llegado a Francia tras los decretos de exclaustración españoles de los años treinta, por lo que debió quedar marcada en la memoria colectiva de ellos la situación que vivieron:

en Cataluña y Levante la vida errante y la mendicidad fue la única salida para muchos religiosos, aterrados por la caótica exclaustración del verano de 1835. Salían de sus conventos como alimañas acosadas, caminando de noche, ocultándose en los boques y temiendo por su vida [...] algunos emprendieron un largo éxodo hacia los pueblos de su naturaleza, buscando refugio entre sus familiares [...] a cada exclaustrado le tocó vivir su propia historia ${ }^{37}$.

No solo tuvieron bienhechores en el momento de la expulsión de Francia, sino que no tardó en organizarse en París el conocido como "Comité de suscripción por los padres franciscanos expulsados" que, promocionado por personas devotas y cercanas a la Orden Franciscana, tenía como objetivo ayudar en las necesidades urgentes de los religiosos. Unas necesidades fundadas en la prohibición de la Orden de poseer sumas de dinero personales, provocando que el ahorro personal de cada religioso fuera nulo. La dispersión conllevó que los gastos se multiplicasen a la par que los ingresos se veían notablemente reducidos. Con todo ello, el objetivo principal era dotar de dinero a los religiosos, ya que no tenían medios ni para lograr los asilos que les habían ofrecido en el extranjero ${ }^{38}$.

36 Bienfaiteurs qui ont offert un asile ou des secours en cas de suppression, AHPFP, Expulsion 1880. El original en francés.

37 Manuel REVUELTA GONZÁLEZ: Vicisitudes y colocaciones de un grupo social marginado: los exclaustrados del siglo XIX,"Hispania Sacra”, 32 (1980), p. 2.

38 Aide apportée aux Franciscains expulsés et expatriés, Comité de souscription pour les PP. Franciscains expulsés (Paris), AHPFP, Expulsion 1880. El original en francés. 


\subsection{El exilio en España}

El gobierno franciscano ya tenía contemplado, como atestigua la reunión definitorial del 29-3-1880, el deseo de llevar a los religiosos a territorios hispanos. El peligro de instalación cerca de la frontera, junto a las restricciones del gobierno español, los escollos jurisdiccionales y la cercanía del mar, decidieron a la provincia elegir los conventos de Soto y Castro (ambos en Cantabria) para noviciado. Además, reflexionaron sobre la posibilidad de alquilar el convento que la provincia franciscana del Perú tenía en Vich (Barcelona), con el fin de ser el lugar de residencia del resto de religiosos. Junto a estos movimientos, el provincial galo encargo a uno de sus religiosos, que estaba en España a finales de 1880, la posibilidad de ir viendo otros lugares para acoger a sus hermanos de religión ${ }^{39}$.

El religioso comisionado para ir tanteando posibles lugares de asilo fue Jean María de Ormiers Quillán que se encontraba en España tomando baños por indicación de su médico. Concretamente es en Gijón donde se entera del futuro incierto de sus hermanos. Desde el norte del país se dirigió a Sevilla, invitado por su tío Luís Ormiers, obispo galo que fundó las Hermanas del Ângel de la Guarda. Esta congregación poseía un colegio en Sevilla ${ }^{40}$, y es precisamente donde el P. Jean Maria fue invitado a realizar una tanda de ejercicios espirituales. En su ruta hacia Sevilla pasó por Ávila (donde vería el antiguo convento de San Antonio) y la Rábida (Huelva). Unas de las peticiones de su provincial consistió en visitar a los obispos para oír los ofrecimientos pero sin comprometerse, ya que estaban en negociaciones con el obispo de Urgel para instalarse en un convento en Balaguer (Lérida). La idea de este convento parecía tan real que ya se tenían planos preparados; sin embargo, entraron en juego varios elementos: por un lado, el gobierno municipal era el dueño del edificio y no parecía tendente a que volviera a su antiguo uso; por otro, el comisario apostólico para la Orden Franciscana presionó al provincial de Cataluña, cuya provincia ya estaba restaurada, para evitar el

39 Estudio sobre la restauración de la Provincia Bética del padre Mariano de San José, AHCL (Archivo Histórico del Convento de Loreto), p. 3.

40 José-Leonardo RUIZ SANCHEZ y Manuel MARTIN RIEGO: Iglesia y educación en Andalucía. Las órdenes y congregaciones religiosas en la edad moderna y contemporánea, en "Anuario de Historia de la Iglesia Andaluza", 2 (2009), pp. 58-61. 
asentamiento, por lo que, pese a las insistencias del obispo, el provincial catalán escribió a su colega galo que:

en el convento de Villareal [Castellón] no hay ni una celda vacía [...] no puedo pues hacer nada en beneficio de los estudiantes de esa provincia. He allí el fruto de la poca armonía que reina entre los franciscanos. Yo hubiera podido abrir algunos otros conventos pero me ha faltado el personal, y en todos partes he hallado más apoyo para la restauración de ésta seráfica, que entre los mismos franciscanos. Todos tenemos que pasar por la penitencia, la cual me temo será para los franciscanos franceses más larga de lo que ellos creen ${ }^{41}$.

La actitud de los frailes catalanes inclinó la balanza hacia el sur peninsular que, en su mayoría, era un gran desierto franciscano y podría evitar más fácilmente entrar en problemas con el franciscanismo español. A esto se unía la promesa del gobierno español al francés de no permitir la instalación de frailes, considerados sediciosos, en los dominios españoles cercanos a la frontera con el país galo. De tal manera las propuestas enviadas por Jean Marie Quillán desde Sevilla se postulaban como la mejor oferta.

J.M. Quillán llegó a Sevilla en verano y pronto recibió, de mano del arzobispo manresano y carmelita Lluch y Garriga (1816-1882), la invitación para instarse en la diócesis, a sabiendas de los tintes que estaba adquiriendo la política gala. El fraile no podía decidir por toda su provincia por lo que comenzó un cruce de cartas con el provincial galo en las que subyace el deseo de aceptar los conventos, pero había varios inconvenientes. El primero de ellos es que se habían iniciado los trámites para adquirir uno en Balaguer, a la par que habían recibido invitaciones de los obispos de Ávila (donde se podrían instalar en el convento de San Antonio) y de Oviedo. Además, se unía la problemática de jurisdicción del comisario apostólico para la familia franciscana en nuestro país: España se hallaba exenta de la jurisdicción del general de la Orden pero no Francia, por lo que los frailes franceses debían ser muy cautos para no incurrir en ilegalidades jurídicas internas, máxime cuando a la altura de 1880 el proceso restauracionista franciscano en España ya estaba muy avanzado.

41 Lettre du Provincial de Catalogne au Provincial de Saint Louis (3-X-1880), AHPFP, Expulsion 1880. El original en francés. 
Los conventos enunciados se fueron descartando sucesivamente: el de Balaguer estaba en poder del Ayuntamiento, sin perjuicio de que los Carmelitas habían pedido también el mismo convento ${ }^{42}$. A lo anterior se unía la actitud del propio provincial catalán que, ante las peticiones del superior galo y del obispo de Urgel para instalar a sus frailes estudiantes en España, no parecía dispuesto a brindarles ayuda.

En Sevilla, el arzobispo les ofreció dos conventos: el de Arahal (al este de la sede arzobispal) y Loreto (en Espartinas, próximo a la ciudad de Sevilla), que se hallaban abandonados, con lo que se hacía necesaria una reforma para albergar a una posible comunidad; pero, por otro lado, se evitaba la jurisdicción del comisario apostólico, un tema recurrente en la correspondencia. También se hacía necesaria la autorización episcopal y del gobierno español, no obstante, ya vimos como el gobierno, desde 1874, aceptaba la mayoría de las peticiones de instalación, sin perjuicio de que su publicación en La Gaceta no se solía dar. Recalcamos la mayoría, puesto que según La Cruz el criterio que parece adoptado por el ministerio de Gracia y Justicia, consiste en entretener indefinidamente la concesión de conventos, si para ellos se pide ayuda al gobierno, conforme al Concordato, y conceder los que se funden, sin ninguna clase de subvención del Estado ${ }^{43}$.

En este contexto, se comprenden las reiteradas exigencias del provincial galo para asegurarse de que la fundación en Sevilla fuera autosuficiente, algo a lo que contribuyeron las muestras de entusiasmo por parte de los pueblos que recibían a los religiosos. El P. Quillán a su llegada a Sevilla no debió tardar en entrar en los círculos eclesiásticos de la ciudad, más siendo un fraile extranjero cuya provincia estaba siendo desmantelada por el gobierno. El ofrecimiento del cardenal Lluch lleva a que el 24 de octubre de 1880 el provincial francés presionara al fraile para que haga instancias acerca del convento de Loreto que le ha ofrecido el Sr. Arzobispo de Sevilla, mientras que vuelve la reiterada insistencia de gran cuidado con la cuestión de la jurisdicción pues no queremos salirnos de la del Rmo. Ministro General ${ }^{44}$.

Se registra documentación municipal tanto de Arahal como de Loreto ofreciendo cuanta ayuda sea posible a los religiosos que vendrán. En el caso del Arahal, era el alcalde quién se mostraba

42 Projet d'installation au couvent de Balaguer, AHPFP, Expulsion 1880. El original en francés.

43 Pedro RIQUELME OLIVA: Restauración de la Orden Franciscana ..., 327

44 Estudio sobre la restauración de la Provincia Bética..., 3. 
entusiasmado y animaba a la fundación; mientras que en Olivares y Espartinas, por lo que hemos podido consultar, se organizan colectas: Sin pedir nada a nadie, ya me han ofrecido más de 5.000 reales y además todo el vino y el aceite de la comunidad durante el año. He visto desproveerse a este condado para proveer todo lo necesario en el convento de Loreto ${ }^{45}$. Esta es la información que Jean Marie Q. le hizo llegar a su provincial a principios de noviembre de 1880, mucho más esperanzadora que la carta del provincial catalán.

A inicios de octubre de 1880, el fraile francés visitó Loreto donde se encontró con que el santuario se hallaba habitado por el exclaustrado de la antigua provincia de Andalucía Juan del Toro, con quien mantendrá cordiales relaciones. Este sucedió a su hermano Miguel del Toro, también exclaustrado, como capellán del santuario mariano de Espartinas, siguiendo la práctica de los obispos de dejar a los exclaustrados como capellanes o rectores de las iglesias de los antiguos conventos.

Buenas debieron parecerle al provincial galo las informaciones que recibía de España cuando comisionó, en noviembre de 1880, a J.M. Quillán para lograr el permiso de establecimiento por parte del gobierno español. No sabemos si fue en Sevilla o en Loreto, pero lo cierto es que el fraile francés entró en contacto con el párroco de Olivares, José Rodríguez, que pareció muy interesado en la refundación del dicho convento. Es él quien firma la información mencionada anteriormente sobre el abastecimiento garantizado para Loreto. También debió ser él, o algún allegado, quién pusó en contacto al P. Quillán con Andrés Plácido Lasso de la Vega y Quintanilla (18271900), VII conde de Casa Galindo, aunque con la trayectoria de este noble parece lógica que fuera recomendada al francés por algún elemento católico de la ciudad.

Si algo debemos destacar en la trayectoria del VIII Conde de Casagalindo para el presente apunte es que era el líder del partido monárquico de Sevilla. Su biógrafo, el IV Duque de Rivas, lo describe como un verdadero demócrata cristiano [... en la vida de Jesucristo y en su Evangelio hallaba los verdaderos principios de igualdad y fraternidad huma$n a s^{46}$. Esta personalidad, junto a su puesto político y social, fue sin duda un gran logro en los planes de los religiosos franceses. Su pertenecía

45 Lettre du 5 novembre 1880 de Jean Marie au Provincial de Saint Louis d'Anjou, AHPFP, Expulsion 1880. El original en francés.

46 Enrique RAMÍREZ DE SAAVEDRA: Bosquejo biográfico del conde de Casa Galindo, Sevilla, 1902, p. 145. 
a la nobleza clásica andaluza, ser Grande de España, junto a la actividad política, lo llevó a ser gobernador en varias provincias, logrando un sitio fijo en el Congreso. La llegada del Sexenio lo llevó de vuelta a Sevilla donde, en fuerte amistad con Cánovas, fue líder del Círculo Alfonsino de la ciudad y conspiró para traer de vuelta la monarquía, siendo encarcelado hasta finales de 1874, cuando es nombrado para el Gobierno Civil de Sevilla. El puesto de gobernador lo compaginó con el de líder del Partido Conservador Liberal hasta $1890^{47}$.

En la misma carta del 5-11-1880, el fraile encargado de la instalación informó de que el Ayuntamiento de Espartinas se mostraba reticente a aceptar a la comunidad pero que se subordinaría a órdenes superiores. Sin duda, el conocer la ayuda del conde debió proveer de esperanza a los frailes y de respeto al Ayuntamiento, ya que, a inicios de noviembre, el noble sevillano se encuentra en Madrid haciendo gestiones con Cánovas y el ministro de Gracia y Justicia, mientras que el francés desea que el alcalde de Espartinas realice una carta de petición al gobierno español para dársela al conde que, en mano, se la entregará a Cánovas que es lo que ha hecho hasta ahora.

Debemos sospechar que la instalación corría prisa porque con la negativa de otros territorios quedó Sevilla como la última opción, con lo que entendemos que el 11-11-1880 J.M. Quillán vuelva a escribir a su provincial contándole los avances. En la correspondencia el entusiasmo del duque de Casa Galindo parece alto, el mismo fraile acude a Madrid, junto al cura de Olivares, e intenta tener una audiencia ante el ministro, donde deseaba entregarle una carta de recomendación del arzobispo de Sevilla, otra de un médico madrileño que parece ha leído sobre nosotros, y que además le presentó al obispo auxiliar de Toledo, Ciriaco Ma Sancha y Hervás (1833-1909). Este prelado acudía al gobierno para gestiones privadas, por lo que juntos decidieron ir, pero no encontraron al ministro sino a su secretario, al que describe como excelente católico. Narra esta carta, siguiendo las palabras del secretario, que el protocolo a seguir para el asentamiento sería el siguiente: presentación ante el ministro, informes del Gobierno Civil de la provincia y del arzobispo que, en el caso de ser favorables, son enviados al Ministerio de Hacienda, donde, si son positivos los resultados, se trasladan al ministro de Gracia y Justicia que da la aprobación.

47 María SIERRA ALONSO, Partidos y líderes políticos en la Sevilla de la Restauración, en“Revista de Historia Contemporánea" 7 (1996), p. 96. 
La concesión del convento de Loreto la daban por hecho, aunque habrá que tener paciencia, y esperan a la concesión del ministro. Durante los días en Madrid debió surgir amistad entre el arzobispo y el fraile, ya que el primero es el que se queda encargado de recibir a los religiosos y darles un hospedaje antes de partir a Sevilla. Los exiliados se alojaron en el convento de los Padres Escolapios (calle Hortaleza), donde fueron atendidos hasta su marcha. En un apartado anterior ya comentamos que los frailes franceses no poseían dinero, por lo que se hizo necesario la participación del Comité de ayuda a los expulsados, encargado de financiar el viaje desde Francia a Sevilla.

No se confundía J.M. Quillán cuando señalaba que el arzobispo era tendente a la instalación ya que éste contesta a la petición del gobierno con estas palabras:

la sola enumeración del proyecto ha llenado mi alma de mucho consuelo, satisfacción y alegría porque creo que el restablecimiento de una Comunidad en aquel convento de Religiosos de una Orden tan esclarecida como la de San Francisco, que sirva según su propia regla, no podrá menos de producir muchos santos de condición, enseñando al pueblo con el ejemplo y la palabra las virtudes cristianas de que tan olvidado se halla, debido a las falsas proposiciones que se le hicieron en año pasados de infausta recordación; pues aun cuando es cierto que los Párrocos hacen cuanto esfuerzos les son posibles para conseguirlo, las múltiples obligaciones a que continuamente tienen que atender, no les permiten obtener el resultado que sería de desear, y por lo mismo se hace necesaria cada día más y más la eficaz cooperación de otros operarios evangélicos, que, libres de tantas obligaciones como las que pesan sobre los párrocos, pueden dedicarse con más constancia y mayor aprovechamiento espiritual de los fieles, a la predicación de la divina palabra, al confesionario y al cumplimiento de todos los demás cargos el ministerio sacerdotal; y este es precisamente el vacío que vendría a llenar la Comunidad de Religiosos Franciscos...creyendo por lo mismo que no solo es conveniente sino necesario su establecimiento, para el buen servicio espiritual de esta dilatada diócesis ${ }^{48}$.

En el mismo tono fue la respuesta elaborada para el informe de Gracia y Justicia (29-11-1880) en la que se insiste sobre la urgente necesidad que hay de que a la mayor brevedad posible se establezca la comunidad ${ }^{49}$.

\footnotetext{
48 Carta del Arzobispo de Sevilla a fray Jean María Quillan (X-1880), AGAS. FA, sec. II, OO.RR Masculinas, leg. 5273, exp. 5.

49 Ibid...
} 
El arzobispo parecía darles la razón a los propios religiosos franciscanos españoles cuando manifestaban sobre el clero secular que:

[...] más que su magnífica tropa de línea, la cual se bate, no hay duda, con el brío que todos vemos; pero ¡ay!, faltan misioneros a nuestros campos y ciudades; faltan agonizantes a nuestros enfermos; faltan sabios a nuestras academias; faltan oradores elocuentes a nuestros púlpitos; alta majestad a nuestro culto; porque, aunque el clero secular da individuos sobresalientes en cada uno de estos ramos, no da para todas las necesidades; han desaparecido los semilleros que estaban dotados para eso de especial fecundidad $[\ldots]^{50}$.

Por otro lado, parte de la prensa sevillana no se mostraba muy entusiasmada con la noticia y parecía ejercer presión para evitar la concesión:

Estamos en plena invasión de frailes [...] En Nuestra Señora de Loreto se establecerá pronto una comunidad de menores observantes de los expulsados de Francia. Los religiosos benedictinos han pedido hospitalidad al arzobispo de Sevilla, y el señor Lluch se la ha ofrecido con mucha complacencia en su palacio de Umbrete, a tres leguas de esta ciudad... Tales son las órdenes monásticas que muy pronto habrá en la diócesis de Sevilla, además de las que hoy existen: por lo menos estas son de las que tenemos noticias... ${ }^{51}$.

Tal y como hemos apuntado sobre el anticlericalismo de la Restauración, se había pasado de las antorchas a las imprentas debiendo en este momento contextualizar el escrito en el anticlericalismo intelectual con poca violencia real. No es nuestro objetivo analizar la prensa del período pero no podemos olvidar que es transmisora de una realidad. No era el catolicismo lo imperante en la España de los inicios de la Restauración, siendo la prensa quien construye un discurso el cual, considerado como acto de habla, lleva la intención de informar al público lector $y$, al mismo tiempo, de influir en él al proponerle su propia lectura de los acontecimientos ${ }^{52}$. A lo que se une que las ideologías organizan actitudes específicas de los grupos, estas actitudes pueden intervenir

Revista Franciscana, 8 (1873), pp. 236

La Voz: Diario de la Mañana, 27-XI-1880.

2 Susana GONZÁLEZ REINA: Reflexiones teórico-metodológicas para caracterizar al discurso de la prensa escrita como discurso político, en "Revista Mexicana de Ciencias Políticas y Sociales", 208 (2020), p. 99. 
en la formación opiniones personales representadas en modelos ${ }^{53}$. Queda claro que la información transmitida crea una idea en el receptor, en este caso el lector, y este concepto transmuta en identidad al otorgarla a un colectivo diferente a nosotros, al otro. Ese otro se veía plasmado en el aluvión de fundaciones que se estaban dando en la diócesis de Sevilla de las que nos habla La Semana Católica:

1. Una comunidad de frailes franciscanos menores observantes en el antiguo convento de Ntra. Sra. De Loreto; 2. Una residencia de antiguos padres carmelitas en su antigua iglesia del Ángel en Sevilla; 3. Un asilo de ancianos, asistido por Hermanitas de los Pobres en la villa de Osuna; 4. Se inauguró una espaciosa casa noviciado para las Hermanas de la Cruz, en Sevilla; 5. Se han establecido las Hermanas del Santo Ángel, en la ciudad de Huelva; 6. Se han instalado los Padres Salesianos, en la ciudad de Utrera... ${ }^{54}$.

Los proyectos de los religiosos no pararon sino que, dando por hecho las gestiones, comenzaron a preparar el viaje. La reunión del definitorio de noviembre de 1880 no lograba aún decidir el destino, diciéndole a J.M. Quillán que van a salir religiosos pero que no saben si con destino a Loreto o a Arahal, organizando que si reciben los dos conventos, se destinará en uno a los estudiantes, mientras que los novicios irán al otro.

Las dilaciones del gobierno en contestar provocaban indecisión y tensión entre los propios religiosos. Muchos ya estaban siendo enviados al sur de Inglaterra y a Holanda ${ }^{55}$, mientras que el gobierno español se decidía a contestar el 20-12-1880 en términos positivos pero conminando a los religiosos para acudir al Ministerio de Hacienda a pedir la concesión ${ }^{56}$. Resulta interesante el fragmento citado a continuación ya que permite plasmar la práctica política de la Restauración sobre los religiosos: por parte del poder civil no hay inconveniente alguno en que los mismos residan en él, viendo conforme a las instituciones de su Orden y prácticas de su instituto. Por tanto, ya no se

53 VAN DIJK, T.: Opiniones e ideología en la prensa, en "Voces y Culturas", 10 (1996), p. 15.

54 La Revista Católica, 218 (1880), p. 70.

55 Hugues DEDIEU: Flashes sur l'historie de la Province Franciscaine p. 16.

56 Contestación del Arzobispo al a la Real Orden de 20-XII-1881, AGAS. FA (Archivo General del Arzobispado de Sevilla. Fondo Arzobispal), sección II, órdenes religiosas masculinas, legajo 5273, expediente 10/1. 
busca la disolución ni la erradicación sino que se permite la reunión de personas para la vida consagrada.

Unos días después de que el Arzobispado de Sevilla recibiera la carta anterior (en concreto, el 20-12-1880), escribió a Madrid dejando claro que si bien en la Real Orden se dice que los religiosos se dirijan a Hacienda, creo no obstante esto, que no se encuentran en el caso de tener que practicar esta diligencia, toda vez que el citado Convento ha estado siempre en poder de esta dignidad arzobispal, quien en todo tiempo y aún tienen en la actualidad al frente de él dos capellanes de la misma Orden para el sostenimiento del culto divino en el mismo... en este supuesto, he cedido y cedo desde luego a la referida comunidad con el objeto de que queda expresado el mencionado convento de Loreto ${ }^{57}$.

A pesar de todas las gestiones el definitorio galo parece ser que declinó la oferta de Loreto y se decidió por Arahal en diciembre de 1880. La determinación de los superiores no debió sentarle bien a J.M. Quillán, quien seguía en Madrid haciendo gestiones y procurando la rápida resolución de los problemas. Es cierto que Arahal y Loreto tenían diferencias. El primero solo necesitaba la aceptación del gobierno y del arzobispo, sin embargo su situación era más lejana de la ciudad de Sevilla y perteneció a la familia de los franciscanos descalzos, por lo que una posterior restauración de los mismos podría ocasionar problemas jurisdiccionales. Loreto, en cambio, necesitaba ambas aprobaciones y la exención jurisdiccional de la Comisaria, pero su cercanía a Sevilla y las facilidades que, por la misma situación ofrecía, lo hacían una propuesta difícil de dejar pasar.

A primera vista parece que la cuestión de jurisdicción atañaba más al régimen interno de los franciscanos, evitando así conflictos jurisdiccionales. No obstante, los propios españoles también buscaban depender directamente del general de la Orden. Riquelme Oliva recoge las palabras del provincial catalán R. Buldú que ya en 1876 , en relación a la restauración de las comunidades españolas, escribió como querían también la filiación inmediata con el general de la Orden y no tener jurisdicción exenta, en pos de evitar a escribas y saduceos, o sea, los liberales, que procuran destruir la Orden para poder más fácilmente destruirla ${ }^{58}$. Sin duda, el proceso unificador comenzó antes. Ya en 1862, dentro de la familia franciscana, había voces que

57 Ibid...

58 Pedro RIQUELME OLIVA: Restauración de la Orden Franciscana..., 331 
pedían la unificación de todo el mosaico de tipos del franciscanismo (observantes, recoletos, descalzos y reformados) bajo el nombre común de "franciscanos" y compartiendo régimen jurídico ${ }^{59}$. Unas iniciativas que culminarán en 1897 con la constitución apostólica Felicitate quadam ${ }^{60}$. En 1880 la familia franciscana seguía dividida en reformas y formas de entender la regla.

J.M. Quillán seguía en Madrid alojado, en los Escolapios de la calle Hortaleza. La espera se debía a su decisión (tal y como comunicó a Francia el 11-11-1880) de aguardar allí a los religiosos y acompañarlos, siempre que fuera posible, hasta Sevilla. Sabemos, ya que tenemos conocimiento del final del viaje, que fue Loreto el último destino, algo que no lo tenía tan seguro J.M. Quillán En la misma carta le contaba a su provincial como:

En el caso de que los religiosos no vengan ni a Loreto ni a Arahal irían a Morón, un antiguo convento de Sevilla de nuestra Orden que pertenece a los propietarios muy fieles a los religiosos franciscanos, a los cuales quieren establecer en el convento, y si es necesario iré a verlo ${ }^{61}$.

Hemos apuntado como el arzobispado hispalense notificó al gobierno que no era necesario que los religiosos pidieran permiso al Ministerio de Hacienda. Tampoco se dan noticias de la llegada de frailes. Bien pudo ser que enero fuera el mes en que más se discutió, entre los propios franceses, el destino final de los religiosos dentro de la diócesis. En febrero de 1881, concretamente el día 5, el arzobispado se expresó en los siguientes términos:

Fr. Juan María de Quillán, procedente de la comunidad de religiosos franciscanos de Bourges, en Francia, es el encargado por el R.P Provincial de la misma para disponer y preparar su instalación en el antiguo convento de Nuestra Señora de Loreto, término de Espartinas en este nuestro Arzobispado, autorizado para este objeto por Real Orden de 20 de diciembre último. Por lo que mandamos a los curas, al capellán de dicho santuario y a las demás

59 Lázaro IRIARTE DE ASPURZ: Historia Franciscana..., 440.

60 Disposición de León XIII mediante la cual se decretaba la unión bajo el “Ordo Fratrum Minorum" con mismas constituciones, mismo hábito, un solo ministro general. Era tal la decisión del pontífice que amenazó a aquellas provincias reticentes con la disposición con prohibirles admitir novicios, lo que provocaría el envejecimiento de la misma. En Ibid..., 441.

61 Lettre du 11 novembre 1880 de Jean Marie au Provincial de Saint Louis d'Anjou, AHPFP, Expulsion 1880. El original en francés. 
personas de nuestra jurisdicción, que cooperen eficazmente por su parte a la realización del encargo confiado a fray Juan María de Quillán; y portador de estas nuestras letras; y a las Autoridades civiles rogamos se sirvan, en caso necesario, prestarles su apoyo y protección con el propio objeto ${ }^{62}$.

La espera de J.M. Quillán y sin duda del párroco de Olivares, los exclaustrados rectores de Loreto, del conde Casa Galindo y otros tantos que desconocemos se vio culminada el 5 de febrero de 1881. En ese año, los religiosos llegaron a Sevilla en varias partidas, siendo recibidos en el Seminario Mayor por su rector, sin duda movido por los deseos del arzobispo hispalense que deseaba tenerlos en mi diócesis, serán bien recibidos con alegría pos estos buenos católicos andaluces y por mí [...] saluda en mi nombre a esos valientes religiosos ${ }^{63}$. Las muestra de acogida del arzobispo las podemos interpretar de diferentes formas, en nuestra opinión poseen un claro matiz paternalista. Esta apreciación confluye, en consonancia a todo el episcopado español del período, en la acogida a los religiosos ayudándolos, nacionales o foráneos, en tanto habían sido los obispos sus representantes ante el gobierno durante toda la exclaustración. También habían sido ellos los que habían lidiado con el gran problema de los exclaustrados, su colocación y con la casi extinción de las órdenes religiosas. Por tanto, ello unido al carácter de religioso del arzobispo, que recordemos perteneció a la Orden carmelita, provocó un caldo de cultivo idóneo para que la restauración religiosa se diera de manera fructífera, más aún cuando el mismo gobierno la bendijo y amparó. A lo anterior debemos añadir que los religiosos franceses, por su misma peculiaridad, no se hallaban en un largo exilio a base de pensiones estatales, como podría ocurrir con los exclaustrados españoles, sino que su reciente supresión conllevaba que, aunque con esfuerzo, fueran autosuficientes y no dependieran de subvenciones estatales sino del ya comentado comité y personas afines.

Con el decreto del 5-2-1881 se iniciaba la vuelta oficial a Sevilla, tras casi cincuenta años de ausencia, de la observancia franciscana. Sin embargo, la llegada no fue inmediata. El convento de Loreto tenía los claustros arruinados a pesar de los desvelos de los capellanes del

62 Copia de autorizaciones arzobispales, Sevilla 5 de febrero de 1880, AHPFP, Expulsion 1880.

63 Copia de autorizaciones arzobispales, Sevilla 23 de noviembre de 1880, AHPFP, Expulsion 1880. El original en francés. 


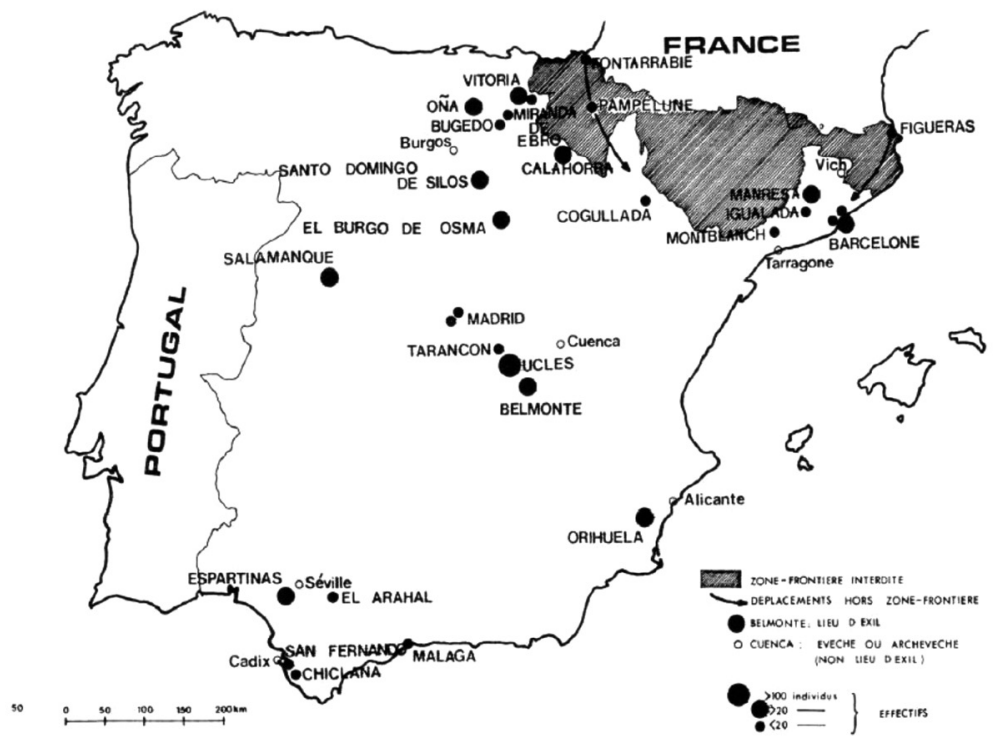

Asentamiento de congregaciones religiosas francesas en España durante 1880-1883 ${ }^{64}$

santuario, por lo que aún había que realizar obras. Tampoco era seguro que los religiosos vinieran a Loreto, de hecho apuntamos como el definitorio galo rehusó el convento en diciembre pero la mediación del padre general inclinó la balanza. A pesar del peso del padre general, el provincial francés aún no estaba seguro de aceptar el convento, escapándose de nuestro conocimiento el por qué de tanta prudencia; decidiendo en abril venir a España para visitarlo personalmente. Las impresiones que recibió no debieron desagradarle cuando escribió una circular a su provincia en la que expresaba sus ansías por instalar en este bendito lugar una buena y ferviente comunidad ${ }^{65}$.

Con la venía del provincial se iniciaba el exilio en el que se guardaba también la precaución de que los frailes escribieran de su puño y letra unas cartas en las que declaraban: Mi reverendo padre. Acepto de todo corazón todos los inconvenientes que puedan ocurrir como resultado de mi alejamiento de Francia. Estoy listo para ir a donde la obediencia me lleve ${ }^{66}$.

64 Fuente: Jean Marc DELAUNAY: "Des réfugiés en Espagne: les religieux français..., 300

65 Marcel LAUNAY: Hélène de Chappotin et les Franciscaines..., 10.

66 Consentement des étudiants qui se sont rendus en Espagne ou en Angleterre, AHPFP, Expulsion 1880. El original en francés. 


\section{LA INSTALACIÓN DE LOS RELIGIOSOS (1881-1883)}

La llegada al poder de Sagasta (1881-1883) avivó los temores de los superiores franceses que lo consideraban masón y veían peligroso enviar a los estudiantes a España con este nuevo cambio ${ }^{67}$. Debió tranquilizarles el comprobar que no había ninguna alteración notable en la política religiosa, que la norma establecía dar los permisos de instalación, independientemente de la ideología conservadora o liberal, para cada casa o comunidad ${ }^{68}$. El mismo provincial Rafael de Aurillac, junto a otros hermanos, visitó Loreto entre marzo y abril de 1881, sin perjuicio de pasar también por varios conventos, situados principalmente en el norte del país, asegurándose una alternativa por si Loreto no pudiera ser finalmente habitado. El viaje de vuelta había sido planeado para pasar por conventos como el de Soto y ver al provincial franciscano de Cantabria, pero una vez visitado Loreto, la decisión estuvo tomada.

El 6-5-1881, tras más de cinco meses de gestiones, recibió J.M. Quillán la carta que le informó de que la provincia había aceptado el convento de Loreto y se disponía a enviar la primera remesa de hermanos $^{69}$. Los documentos a los que hemos podido acceder no concuerdan en el número de hermanos. Los religiosos siguieron el itinerario que había realizado su provincial hacia menos de un mes (Pau - Bayona - Irún - San Sebastián - Zarauz - Azpeitia - Zumarraga - Alsasua - Pamplona - Olite - Casetas - Madrid - Sevilla ${ }^{70}$ ), encontrándose con un convento reformado para poder hospedar a la nueva comunidad. En total, se puede estimar que vinieron dos partidas de hermanos que constituyeron una comunidad de unos treinta frailes distribuidos de la siguiente: quince franceses, seis españoles

67 Estudio sobre la restauración de la Provincia Bética del padre Mariano de San José, AHCL, p. 6.

68 Pedro RIQUELME OLIVA: Restauración de la Orden Franciscana en España..., 327

69 Por ser la primera comunidad observante franciscana que se asienta en la Sevilla post exclaustración creemos interesante anotar sus nombres: Presidente de la nueva comunidad y vicario el padre Otón, a la par que dará clases a los estudiantes el padre Atanasio, junto a ellos vendrán los estudiantes Cipriano, Samuel, Marcos y Tadeo. Todos franceses

70 El itinerario del viaje quedó registrado en el libro de pagos del Comité parisino de ayuda a los religiosos expulsados, en: A.H.P.F.P. Aide apportée aux Franciscains expulsés et expatriés, Comité de souscription pour les PP. Franciscains expulsés (Paris), AHPFP, Expulsion 1880. El original en francés. 
(pertenecientes a la misma provincia de San Louis de Anjou), y el resto se desconoce. Dicho de otra forma: quince coristas, ocho legos y diez sacerdotes.

La vida de esta comunidad mixta de franceses y españoles no debió ser fácil. El clima del sur peninsular (su comunidad de origen, Bordeaux, en el centro de Francia), el idioma, las costumbres, la religiosidad popular española y diferencias en la administración de la casa pronto comenzaron a hacer mella entre ellos. Los estudiantes también se hallaban separados de sus compañeros, en concreto, la mitad de ellos fueron enviados a Clifton (Inglaterra) para seguir allí sus estudios. El Aljarafe y la sociedad católica sevillana los identificaba como un grupo homogéneo que había venido a perpetuar los fastos gloriosos, que en virtudes y celo apostólico nos legaron los religiosos ilustres que, hasta los días nefastos de la exclaustración, moraron en aquella santa casa ${ }^{71}$.

El recibimiento a aquellos frailes se realizó de la manera acostumbrada en el período: el auxiliar del arzobispo Beato Marcelo Spínola presidió la procesión que culminó en una Exposición del Santísimo, misa pontifical, sermón sobre los religiosos, Te-Deum, corona franciscana $^{72}$ y el establecimiento de la clausura canónica. Con el rito quedaba instaurada la presencia franciscana oficial en la diócesis de Sevilla, comenzando por el convento de Loreto, considerado siempre como casa madre de la antigua provincia franciscana (además de ser santuario mariano, fue casa de recolección -conventos donde la regla se vivía con mayor observancia- de la antigua provincia y casa de estudios).

De los exclaustrados que habitaban la comunidad solo quedaba el conocido como P. Juan. El P. Miguel, exclaustrado que regentó el santuario, murió en 1875, mientras que de los PP. Manuel Rocha y Cristóbal González no hemos encontrado noticias posteriores. El P. Juan quedó inserto dentro de la estructura conventual, con voz en el discretorio (recordemos que era la reunión de los hermanos elegidos por el convento para asesorar al guardián), algo extraño si nos atenemos a las disposiciones que el padre Buldú, provincial catalán, hizó

71 Ángel ORTEGA: Historia de la imagen y santuario de Loreto, Lérida, Imprenta Mariana, 1906, p. 65.

72 Oración mariana similar al rosario y propia de la Orden Franciscana, se compone de siete misterios que repasan las siete alegrías de la Virgen María: Encarnación, visita a su prima Isabel, nacimiento de Cristo, adoración de los reyes magos, hallazgo del niño en el templo, aparición de Jesús resucitado, y la Asunción y coronación de la Virgen. 
al ministro general en 1876 sobre los exclaustrados y la restauración: llegado la ocasión oportuna de restablecer nuestra Seráfica Orden [...] no deben ser, a lo menos en general, los que viven hace muchos años fuera del claustro [...] han adquirido ciertos hábitos que no se avienen con la rigidez de nuestro instituto ${ }^{73}$. Es cierto que estas palabras se insertaban dentro de los proyectos españoles, con las características propias de la Orden de nuestro país, pero nos permite abrir dos vías de investigación: por un lado, se pone de relieve una ausencia notable en que no acudieran exclaustrados españoles de la antigua provincia andaluza a la refundación para volver al claustro; por otro lado, parece que la presencia de frailes extranjeros no era vista con buenas miras por parte de los exclaustrados que aún quedaban vivos ${ }^{74}$. La respuesta a sendas suposiciones la encontramos en que los nacionales tenían recelo a los religiosos extranjeros o a reingresar en un convento bajo la observancia estricta de la regla tras muchos años de inobservancia.

Nuestro análisis se inclina más por pensar en una mezcla de jurisdicción y recelos como ya apuntó fray Sebastián García ${ }^{75}$. La hipótesis que sigue el citado autor, y que no hemos podido confirmar pero que concuerda, es que el último comisario provincial de la antigua Provincia Bética Francisco de Paula Carrillo no reconoció la jurisdicción de los frailes franceses. Puede parecernos poco lógico, pero éste exclaustrado era hijo de la antigua provincia, poseía los sellos que como un testigo se iban legando los comisarios, por lo que es entendible que no quisiera dar los sellos de la antigua provincia a los religiosos franceses que, para más inri, se regían por una jurisdicción diferente al resto de la Orden en España. A esto le debemos sumar que no era intención de los galos recuperar el viejo franciscanismo

73 En Pedro RIQUELME OLIVA: Restauración de la Orden Franciscana en España..., 335.

74 Las relaciones entre los exclaustrados sevillanos y los religiosos franceses no debieron ser buenas cuando en 1885, con la muerte del último comisario provincial de la antigua provincia Bética, los sellos de la misma no son legados a ellos, y la propia iglesia de San Buenaventura es dada por el arzobispado a un sacerdote secular a pesar de peticiones de los franceses para establecerse en el corazón de la ciudad.

75 Fray Sebastián García Rodríguez (1927-2015) fue cronista de la Provincia Bética Franciscana y realizó un primer acercamiento al tema en 1999 con motivo del centenario de la Restauración en: Sebastián GARCIA RODRÍGUEZ: La provincia Bética de la Orden de los Frailes Menores, Guadalupe, Real Monasterio de Guadalupe, 1999. 
Sello de la provincia franciscana de san

Louis de Anjou (siglo XIX)
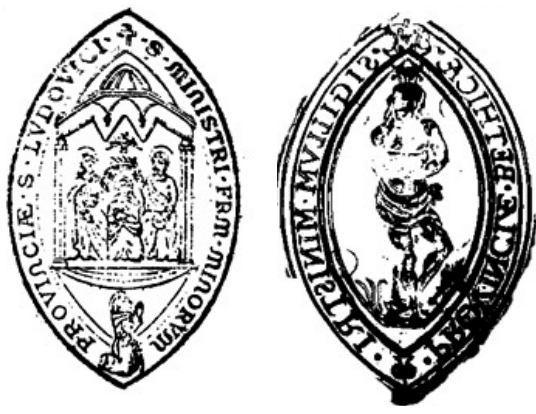

Sello de la provincia observante de Andalucia o Bética

hispano sino utilizar España como un espacio tolerante donde seguir la vida religiosa hasta que tiempos mejores les permitiera volver a Francia. Por lo que, por desinterés de unos y desconfianza de otros, en 1881 no se dio un relevo para refundar la antigua provincia.

Los religiosos, ya instalados en Loreto, se rigieron como lo que eran: un convento más de la provincia franciscana francesa de San Louis de Aquitania, pero en suelo extranjero. El verano de 1881 estuvo protagonizado con la llegada continua de religiosos, muchos de ellos instalados temporalmente en el convento de Soto, hasta conformar una comunidad de unos treinta religiosos, la mayoría franceses, bajo la presidencia de J.M. Quillán. El mismo gobierno de la Orden en Roma supuso las dificultades que debían surgir en un escenario tan poco previsible, lo que llevó a dictar una serie de consejos para la comunidad mediante una circular. En el texto, fechado el 24-6-1881, se recomienda a los religiosos el estudio del español (al igual que hacen los misioneros cuando van a una país extraño), rezar oraciones propias de España, asumir las costumbres nacionales de forma prudente y servirse, siempre que pudiesen, de la lengua vulgar ${ }^{76}$. En la misma carta se concedía la recepción de novicios, con lo que la provincia francesa podría seguir formando a aquellos que quisieran consagrarse, a la vez que se alimentaba a la propia provincia en un tiempo de persecución.

A tenor de la documentación consultada parece ser que en estos primeros meses no surgieron disputas dignas de mención, más allá de anécdotas referidas al uso de la lengua castellana. Por su parte, se desplegó una intensa actividad misiones, siempre limitadas al escaso manejo que del castellano tenían la mayoría, que los llevó en este

76 Estudio sobre la restauración de la Provincia Bética del padre Mariano de San José, AHCL, p. 19. 
primer año a pueblos como Jerez, Marchena, Arahal, Sevilla, Valverde del Camino, Bollullos del Condado, ... Tal carga de actividad misional se veía motivada por: los consejos del arzobispo de intensificar la presencia de la nueva comunidad en la comarca; y por el hecho de que las misiones populares siempre han sido un medio por el que el catolicismo intentaba volver a tener presencia en un territorio donde estaba desaparecido circunstancialmente (o directamente nunca había estado). En el caso de la diócesis de Sevilla, toda vez que los religiosos se encuentran con un territorio donde su presencia era un recuerdo, se une la iniciativa que desde la seo se venía lanzando desde 1878 la conocida como"Piadosa Unión de Operarios Evangélicos". Todos, aunque con diferentes carismas y matices, tenían un método de misión similar: predicaciones, eucaristías multitudinarias, exposiciones del Santísimo y confesiones, en un ambiente que involucraba a toda la localidad y suponía un gran acontecimiento.

Los estudios sobre las misiones populares en la diócesis de Sevilla, campo en el que Ruíz Sánchez ${ }^{77}$ ha desarrollado parte de su investigación, nos permiten apuntar la presencia exponencial de misiones regidas por franciscanos a partir de $1883^{78}$.

\begin{tabular}{|c|c|}
\hline Año & Número de misiones \\
\hline 1881 & $\mathrm{x}$ \\
\hline 1882 & $\mathrm{x}$ \\
\hline 1883 & 2 \\
\hline 1884 & 1 \\
\hline 1885 & 3 \\
\hline
\end{tabular}

Si bien la comunidad parecía funcionar ya que las misiones significaban la salida de sacerdotes españoles a predicar, dejando a la mayoría francesa, la situación interna cambió a inicios de 1882 cuando

77 Sobre las misiones en el siglo XIX en la diócesis de Sevilla: José Leonardo RUIZ SANCHEZ:"Frente a la secularización y el laicismo en la Edad Contemporánea. Las misiones populares en la Archidiócesis de Sevilla", Anuario de Historia de la Iglesia andaluza, 10 (2017), pp. 11-45; José Leonardo RUIZ SANCHEZ:“Cien años de propaganda católica: las misiones en la Archidiócesis Hispalenses (18481952)", Hispania Sacra, 50 (1998), pp. 31-76.

78 Síntesis de la información expuesta en: José Leonardo RUIZ SANCHEZ: Frente a la secularización y el laicismo en la Edad Contemporánea. Las misiones populares en la Archidiócesis de Sevilla, en "Anuario de Historia de la Iglesia andaluza", 10 (2017), pp. 11-45 
el elemento de unión entre franceses y españoles moría. El 25 de marzo falleció J.M. Quillán, ${ }^{79}$ dando comienzo los problemas entre los miembros: al clima del sur peninsular se unía la falta de espacio y el escaso esfuerzo de adaptación que los franceses hacían por predicar en castellano, sin perjuicio de la constante carencia de fondos. La actitud de los foráneos se basaba en estar pendientes de sí mismos: en ellos primó el reclutamiento de futuros frailes franceses antes que cualquier otra actividad. Les faltó apertura al marco geográfico y humano ${ }^{80}$, junto al poco interés que tenían por el aprendizaje de la lengua castellana y las devociones propias de la piedad popular. La falta de espacio se intentó suplir con una nueva fundación en Arahal, que ya tenían concedida, antes que Loreto, pero se produjo un cambio en la municipalidad y el nuevo secretario no era partidario de la fundación ${ }^{81}$.

El nuevo guardián Otón de Pavía seguía con las obras de mejora del convento de Loreto por lo que se asumía que la presencia franciscana había llegado para quedarse. Entre las nuevas realizaciones, se procedió a reparar los claustros altos, la biblioteca y se construyó una hospedería. A pesar de que esto supuso una mejora en las condiciones de vida, no renunciaron a una nueva fundación. Los primeros pasos fueron dirigidos hacía Morón de la Frontera, donde el padre Mariano (religioso franciscano de origen catalán que llegó desde Francia) predicó en mayo de 1882 y volvió, sin duda tras hablar

79 "Rdo. Padre Juna María Ormiers [...] Renunciado a la herencia de la familia, a la edad de 33 años pidió en Bourges, Francia, el burdo sayal de San Francisco, recibiéndolo el 15 de Agosto de 1872, dando desde este día su último adiós a Guillau (en Auda) pueblo de su naturales [...] Hechos a los dos años sus votos solemnes, fue nombrado por su provincial, lector de Teología y maestro de novicios [...] Expulsados del vecino Estado [...] su prelado regular le comisionó...para organizar, de entre sus hermanos dispersos, una Comunidad en España, para poder continuar la observancia de la Santa Regla que habían profesado. Sevilla Marzo 27 de 1882", necrología publicada en La Revista Católica, 227 (1882), pp. 213-215. Jean Marc DELAUNAY: Exilio o refugio en España (veinticinco años después), en "Anuario de Historia de la Iglesia", XIV (2005), p. 156.

81 Si bien las autoridades de la Restauración no ponían grandes trabas para el restablecimiento de órdenes religiosas en el territorio español, si se podía ver amenazado el proyecto con un informe negativo del ayuntamiento donde se pretendía la instalación (se podía abducir que la comarca era pobre y que la vida de los frailes, que vivían en la mayoría de las limosnas, supondría una cargar evitable para la zona). En 1883 se nombra la fundación e instalación en Arahal de una comunidad de religiosos pero no hemos podido confirmar la veracidad de la información, pero todo parece indicar que es un error del citado autor. 
con las autoridades civiles y eclesiásticas, con una carta del arcipreste para su provincial:

[...] al venir a este pueblo el reverendo padre guardián del convento de Loreto en esta provincia de Sevilla, hemos experimentado un gran placer porque concebimos la esperanza, mediante Dios, de ver aqui una comunidad. Mis compañeros en la cura de almas, y yo, y todo este pueblo estamos dispuestos a coadyuvar en el establecimiento de una comunidad. Ya el padre guardián pondrá a usted en conocimiento con lo que cuentan por ahora, y convenimos, que si algunos padres se viniesen, desde luego este pueblo se entusiasmaría y podrían reunir lo necesario para lo que quisieren. Es menester tener ánimo: estos fieles son buenos y los esperan con la más viva ansiedad. Aquí contamos unas diez y ocho mil habitantes, la población es rica, muy afecta a los padres de la religión franciscana, y solo estamos doce sacerdotes, que no son suficientes para llenar las atenciones más precisas del culto divino. En ningún otro pueblo podrán estar mejor que aquí $[\ldots]^{82}$.

El provincial galo, a pesar de las insistencias del padre Mariano, no aceptó la fundación, quizás por las condiciones que los propietarios del convento desde la desamortización (Mercedes Auñón y José Revilla) ponían para la instalación: les dejaban el convento para su habitación pero no en propiedad, aunque la compra quedaba abierta como opción. En esa misma misiva, el padre Mariano escribió a su provincial sobre la necesidad de crear un Colegio Seráfico, en camino de reclutar jóvenes para la Orden en Francia o quizás buscando la presencia estable de los franciscanos en la archidiócesis sevillana.

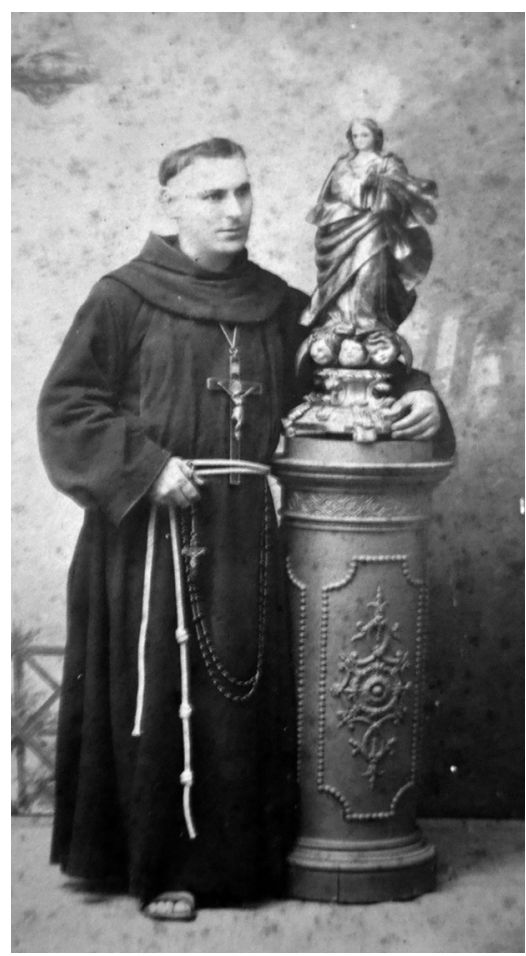

Fray Mariano de San José, cc. $1885^{83}$

82 A propos de la fondation à Morón de la Frontera, 2-V-1882, AHPFP, Expulsion 1880. El original en francés.

83 Fotos sueltas. A.H.P.B.F 
La decisión sobre la idoneidad de levantar el colegio y los posibles gastos que conllevase provocó acaloradas discusiones en los discretorios de los meses siguientes, posicionándose el grupo español a favor y el francés en contra. Aunque pueda parecernos poco significativo, el establecimiento de un colegio seráfico permitía dotar a los jóvenes candidatos, desde su adolescencia, de una formación encaminada a la vida religiosa y/o sacerdotal, elemento que difícilmente se encontraba en la enseñanza pública. Si la Orden Franciscana quería tener personas preparadas y moralmente encauzadas, debía buscar las vocaciones en los niños, normalmente de familias cristianas tradicionales que veían en un hijo sacerdote una de las aspiraciones como modelo de familia. Esta nueva institución, pues la primera de este tipo se fundó en 1869, resultó en un nuevo tipo de religioso, formado integramente en la Orden desde los once o doce años, uniformado en la mentalidad, hábitos, aspiraciones [...] y por esto, muy eficiente para la institución ${ }^{84} \mathrm{y}$, por tanto, para la provincia gala como para dotar de personal una futura provincia en Andalucía.

El P. Mariano se convirtió en guardián sustituto del francés Otón de Pavía, que salió para el capítulo provincial galo de mayo del 1882 en el que fue elegido otro provincial. Ambos llegaron a Loreto en agosto pero no debieron encontrar buen ambiente en la comunidad ni en sus pretensiones cuando la política cambio radicalmente respecto a los españoles. Si el provincial que se decidió por Loreto permitió la entrada de novicios, observando las costumbres españolas, el nuevo gobierno cambió de parecer y no se nombró maestro de novicios, ni se trabajaba para que entrasen jóvenes a tomar el santo habito ni se estableció el colegio y, por otra parte, se quitaron algunas costumbres españolas ${ }^{85}$. Estas decisiones provocaron molestias en el grupo de españoles, llegando incluso a pedir el cambio a una de las provincias franciscanas españolas restauradas. Se sumó que la gran distancia entre Loreto y Francia hacía el viaje muy costoso, que algunos de los religiosos franceses no se adaptan y que el clima era demasiado caluroso. Con estas premisas, el provincial ofreció, bajo obediencia, al P. Mariano que se quedase de

\footnotetext{
84 Lázaro IRIARTE DE ASPURZ: Historia Franciscana..., 430-432

85 Estudio sobre la restauración de la Provincia Bética del padre Mariano de San José, AHCL, p. 31.
} 
guardián y que los religiosos, excepto los coristas, decidieran quedarse o volver a Francia. Los estudiantes, por decisión del definitorio galo de septiembre de 1882, cambiaron a un convento y pese a que en principio se barajó alguno situado en el centro de España, lo cierto es que en diciembre se decidió enviarlos a Inglaterra con el resto de estudiantes ${ }^{86}$.

Junto a los estudiantes también partieron algunos religiosos, provocando a la comarca la idea de que el convento de Loreto volvería a verse deshabitado. En este sentido, desde los municipios de Umbrete y Villanueva del Ariscal, ambos cercanos al convento, escribieron al provincial galo pidiendo suspender esta determinación en beneficio de este pueblo que tanto aprecia a los religiosos, o al menos dejar a los padres de misa y confesión $n^{87}$. Pero las súplicas no surtieron efecto y en la primavera de 1883 salieron los religiosos camino de Inglaterra, sin duda también movidos por la nueva política que se estaba comenzando a adaptar en Francia respecto al clero.

\section{TIEMPOS DE INCÓGNITA: ¿FRANCIA, ROMA, ESPAÑA?}

La marcha de parte de los religiosos trajo consigo dos consecuencias: primero, se limitaron los fondos para el convento de Loreto, en tanto no albergaba a los jóvenes de la comunidad, y en segundo lugar, se redactaron unas constituciones propias para la dicha casa y se asfixiaba la viabilidad de la fundación. Según palabras de fray Mariano de San José, el primer guardián tras la partida, recibió antipatía y mala voluntad [...] y tampoco se nombraba a ningún maestro de novicios español, el P. Guardián sería las dos cosas, y no se hacian mejoras para ingresos de novicios ni arreglar el noviciado ${ }^{88}$. En la citada obra se hace referencia a dos acontecimientos que, por el mero hecho de aparecer, deben consignar alguna realidad, aunque no hemos podido hallar documentos que lo verifiquen. Nos referimos a los problemas entre los frailes a la hora de la partida. El P. Mariano escribió tras la ida: no sé hasta qué punto sea yo culpable de la traslación de los religiosos franceses [...] mi deseo era que

\footnotetext{
86 Marcel LAUNAY: Hélène de Chappotin..., 11-12.

87 Lettres à la province de Umbrete et Villanueva del Ariscal, en Espagne (Mars 1883), AHPFP, Expulsion 1880. El original en francés.

88 Estudio sobre la restauración de la Provincia Bética del padre Mariano de San José, AHCL, 37.
} 
se trabajase para propagar la Orden en Andalucía, cosa que no podía hacerse sin españoles ${ }^{89}$.

Y es que debemos recordar que Andalucía era una Siberia franciscana donde sólo había conventos en Sevilla, mientras que en el resto, como los que en Granada comenzaban a instalarse eran colegios de misiones enfocados a una labor misional exterior ${ }^{90}$. Por lo tanto el deseo de colonizar un territorio vacío y sin reclamaciones sonoras sobre los conventos era una idea apetecible. La no reclamación de antiguos conventos se debe a varias variables, entre las que destaca la elevada edad que la mayoría de exclaustrados tenían en 1880. También es reseñable que con los proyectos restauracionistas se difuminaba la diversidad franciscana, tanto descalzos como recoletos desaparecen, mientras que los colegios de misiones que se fundaban, como el de Chipiona, buscaban mantenerse fuera de la recuperación de las provincias y seguir siendo semillero de vocaciones para el exterior ${ }^{91}$.

Ante tal panorama, el convento de Loreto siguió sujeto a la provincia de San Luís de Anjou pero se redactaron unos estatutos propios para el convento en abril de $1883^{92}$. En el artículo I se hacía mención de la sujeción a dicha provincia para todo, sin perjuicio de ciertas dispensas como aceptar ciertas costumbres españolas (canciones en lengua castellana, sábados de la Inmaculada ${ }^{93}$ ), mientras que en base al artículo IV los clérigos franceses que se han quedado en Loreto quedan sujetos en todo a las normas establecidas para la comunidad española. Punto de intenso debate, y sin duda de frustraciones, supuso el artículo $\mathrm{V}$, según el cual la provincia no responderá de las deudas de la comunidad española ni de las consecuencias de la acogida de nuevos religiosos. Con este nuevo marco la comunidad volvió a escindirse en dos grupos que reflejaban las dos tendencias: pro Francia y pro España.

$89 \quad$ Ibid..., 38.

90 Un estudio sobre la provincia franciscana de Granada en: MiguelVALLECILLO MARTÍN: La provincia franciscana de Granada, Jaén, Fundación Cultura y Misión "Francisco de Asís", 2015.

91 José GARCÍA ORO: Los franciscanos en España. Historia, 286.

92 Règlement spécial pour le couvent de Lorette, avril 1883, AHPFP, Expulsion 1880. El original en francés.

93 La Orden Franciscana siempre ha destacado por su defensa del dogma de la Inmaculada Concepción, por ello ha cosechado una serie de privilegios a lo largo de la historia como, por ejemplo, poder vestir de azul para celebrar la misa de todos los sábados en honor a la Virgen. 
Las consecuencias de la política de la provincia francesa se plasmaron solo un mes después cuando el guardián, el P. Mariano, propuso al discretorio (14-V-1883) la acuciante necesidad de un colegio seráfico y la segregación de la provincia francesa para pasar a la dependencia directa del general de la Orden. Ya vimos como estos deseos de dependencia directa de Roma también estaban fraguando entre las provincias que se venían intentando restaurar, en tal sentido la oportunidad para la comunidad estudiada llegó en verano con la visita del ministro general Bernardino de Portogruario.

Aunque el definitorio las aprobó, parece ser que el entusiasmo no contagió a toda la comunidad ni tampoco con la visita del general. En junio de 1883, el general volvía de una visita canónica a Portugal y de regreso se hospedó en Loreto donde pudo escuchar de primera mano las vicisitudes por las que aquella comunidad estaba pasando. Le expusieron las cuestiones enunciadas dándole el superior general una opinión favorable pero condicionada: el colegio seráfico debía estar fuera del convento teniendo como nexo al rector del seminario, mientras que la desunión con Francia era vista con cautela y les invitó a esperar, ya que a su vuelta a Roma hablaría con el provincial.

No tuvieron reparos en iniciar los movimientos para hacer realidad los proyectos, a pesar de las estrecheces que la comunidad soportaba, años en los que la ayuda de las hermanas del Pozo Santo de Sevilla fue muy destacable. El primer paso encaminado al aumento de la comunidad fue la reapertura del noviciado, nombrando como maestro de novicios al P. Atanasio López, a la vez que se iniciaba una primera misión para recabar vocaciones al norte del país (Cataluña y País Vasco), encabezada por el P. Mariano. La búsqueda de jóvenes en el norte del país tiene un componente sociológico en tanto se pensaba que las personas del norte eran más aplicadas y severas en la realización de la vida religiosa, viejos tópicos que aún hoy podemos observar en ciertos ámbitos. El resultado del viaje fue la entrada en Loreto de cuatro postulantes que fueron rechazados por el discretorio, donde parece que el P. Marcos ejerció el influjo negativo.

La idea del colegio seráfico seguía en la mente de la mayor parte de la comunidad pero se oponían algunas dificultades: falta de personal, de unión, de recursos y de apoyo entre todos los religiosos ${ }^{94}$.

94 Lettre d'Atanasio Lopez, 11 septembre 1883, AHPFP, Expulsion 1880. El original en francés. 
Ejemplo de lo anterior lo encontramos en la carta que fray Marcos escribe a su provincial en septiembre de 1883: Los que han rechazado abrir el colegio seráfico han sido expulsados del discretorio [...] la comunidad no está en estado de abrir un colegio, el guardián tiene la intención de gobernar la comunidad en 5 o 10 lugares $^{95}$.

Pero, como venía sucediendo desde hacía tiempo, la comunidad llevaba dos ritmos distintos y al año siguiente (1884) el ministro general les concede un anhelado deseo: la dependencia directa por dos años para que en 1886 pasarán a depender del comisario apostólico de la Orden en España, pero comenzando a pertenecer a dicha institución en un solo año ${ }^{96}$. Los años de 1884 a 1886 se resumen en una fuerte actividad misionera, pastoral y vocacional, encaminada a afianzar la presencia franciscana en otras localidades. El P. Mariano escribió al provincial galo en 1885 contándole que trabajamos duro para moralizar a la gente. Hoy estoy en Lucena y he predicado en más de 45 pueblos y ciudades diferentes. Hemos dado misiones en muchos lugares, somos numerosos pero con la gracia de Dios nos multiplicaremos ${ }^{97}$. El primer paso se dio en Lucena, donde se funda una comunidad en el convento de Madre de Dios. En esta casa se instaló el noviciado que comienza a funcionar en 1884 con tres novicios, para pasar en 1886 a tener dieciséis. Resulta curioso que en estos años, mientras que se dice el convento se encontraba bajo la jurisdicción del comisario apostólico de la Orden, el Comité de París sigue enviando dinero a Loreto en 1885 y los religiosos franceses siguen teniendo correspondencia con su antiguo provincial. Todo parece indicar que la documentación nos muestra una realidad homogénea que no lo era tanto.

Si Lucena fue fundada en 1885, no tardaron en recibir una nueva oferta proveniente de Morón de la Frontera, ciudad en la que ya intentaron instalarse en 1883 pero que no fue del agrado del definitorio francés. El convento de Morón fue habitado, cc. 1885-1886, por religiosos franciscanos, misioneros de la provincia del Perú bajo jurisdicción del ministro general, pero la escasez de los resultados les hizo abandonar el convento. El abandono debió crear desaliento en

95 Lettre d'Marc-Marie, 12 septembre 1883, AHPFP, Expulsion 1880. El original en francés.

96 Homenaje a la seráfica provincia de Andalucía en el setenta y cinco aniversario de su restauración (1881-1856), Sevilla: Imprenta de San Antonio, p.15.

97 Lettre de Marianus de St. Joseph, novembre 1885, AHPFP, Expulsion 1880. El original en francés. 


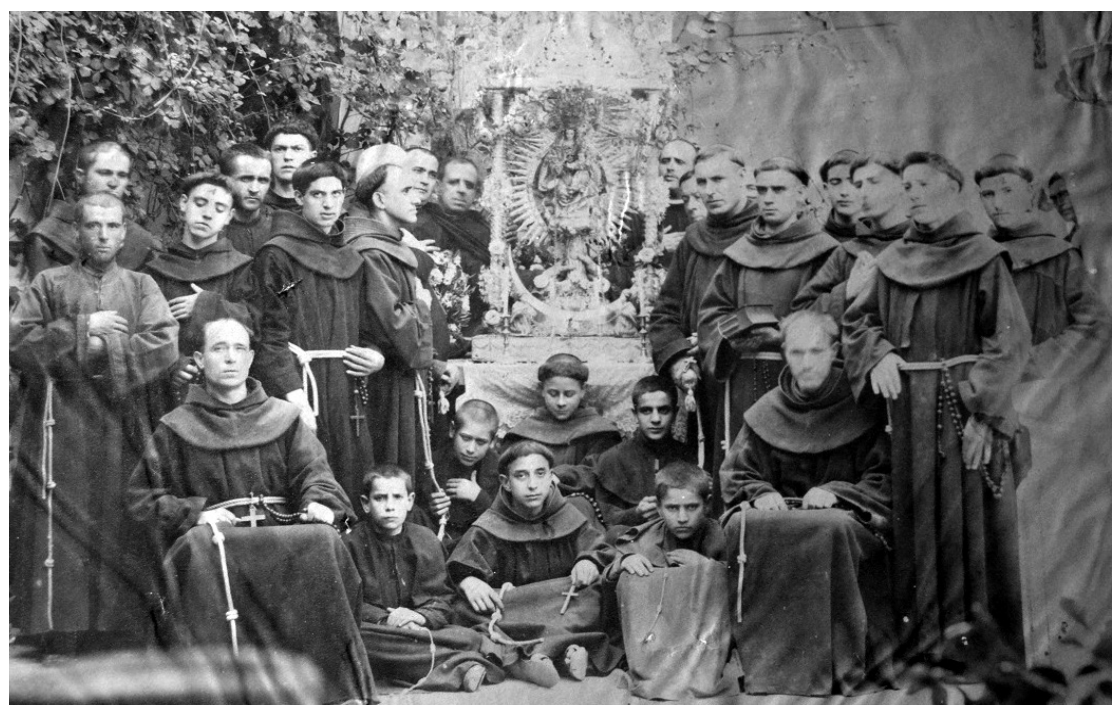

Comunidad del Convento de Loreto $(1886)^{98}$

los superiores de la Orden que veían como Andalucía volvía a despoblarse de hijos de San Francisco, por lo que se pusieron en contacto con la comunidad de Loreto ofreciéndoles la fundación. Tal y como hemos visto el convento de Loreto escaseaba de personal y, si bien se había fundado en Lucena, la división de los hermanos entre dos núcleos no hacía muy viable la aceptación de una tercera casa. La situación fue planteada al general de la Orden pidiendo que la aceptación se realizara si se quedaban en Morón tres religiosos, como así sucedió.

Este panorama fue el que se encontró el P. Francisco Sáenz de Urturi, vicecomisario apostólico, cuando llegó a Loreto el 16 de julio de 1886, una visita que supuso un gran paso en tanto significaba el entroncamiento oficial con el franciscanismo hispano.

La visita del vicecomisario conllevó la vuelta del espíritu de la antigua provincia franciscana observante de Sevilla. En los años siguientes, los frailes fueron adquiriendo diferentes categorías jurídicas, culminando en 1902 con el restablecimiento de la Provincia Bética Franciscana de Andalucía. El proceso se resume en la formación como Custodia (1888), Comisaría (1891) y la restauración

98 Fotos sueltas.A.H.C.L 


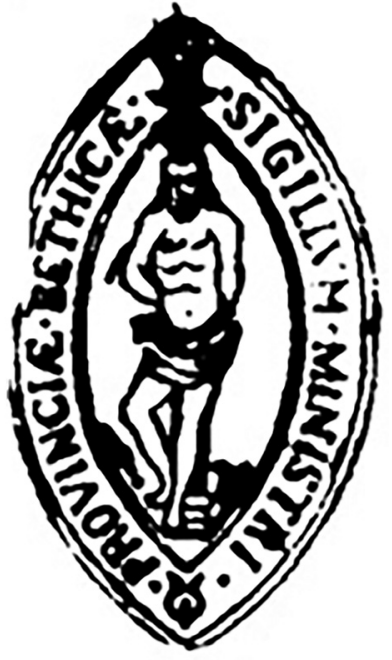

Sello de la Provincia Bética Restaurada (1901-2015) ${ }^{101}$ como tal de la Provincia Bética de Andalucía en $1902^{99}$. La primera reunión de la naciente Comisaría se registró en el Libro de Actas de la antigua Provincia de Andalucía a continuación del último capítulo provincial (1835) con las siguientes palabras:

A los cincuenta años de hacer sido expulsados violentamente los Regulares de España, la providencia de Dios, que vela de un modo especial sobre ellos, ha dispuesto que se restaurara felizmente nuestra Provincia de Andalucía, por lo que se reanudan en este Libro las Actas, en ese lapso de tiempo interrumpidas ${ }^{100}$.

\section{LA VUELTA A LA CIUDAD DE SEVILLA (1889)}

Por haber sido Sevilla sede del franciscanismo observante en Andalucía hasta 1835 creemos oportuno dar unos apuntes sobre el restablecimiento en la ciudad de la primera comunidad franciscana,

99 Como ya apuntamos en este trabajo una mayor profundización en los años de la naciente provincia en los autores: Estudio sobre la restauración de la Provincia Bética del P. Mariano de San José; Historia de la imagen y santuario de Loreto (1906) y Las Casas de Estudio de la Provincia de Andalucía (1917) de fray Ángel Ortega; Los Estudios en la Provincia Bética (1956) de fray Marcelino Barrado Manzano; La provincia Bética de la Orden de los Frailes Menores de fray Sebastián García Garrido (1999); y Los franciscanos en Sevilla (2008) de fray Luís García Chávez.

100 Libro de Actas de la Provincia Observante de Andalucía (1815- ¿?), AHPBF, p. 100.

101 El provincial de la Provincia de Santiago escribe a Mariano de San José en 1890 ante la propuesta de elegir a la virgen María en su asunción como patrona de la nueva provincia restaurada: " hasta ahora se ha considerado [...] que las nuevas provincias [...] se declaren continuación y rehabilitación de las provincias antiguas, conservando todos sus derechos, títulos y pregorrativas, gracias y privilegios; por tanto respecto al titular y patrón debe continuar el que antes tuviera" en: Libro de Actas de la Provincia Observante de Andalucía (1815- ¿?), AHPBF, p. 100. Hoja suelta manuscrita. 
tras más de cincuenta años de ausencia ${ }^{102}$. Aunque hemos comentado la pervivencia del franciscanismo en la ciudad entre 1835 y 1880, no parece que los primeros frailes tuvieran buenas relaciones con los exclaustrados.

La pervivencia en la ciudad de la iglesia de San Buenaventura, con su céntrica posición y el haber sido sede del colegio de estudios de la provincia observante de Andalucía, posicionaba a la ciudad como la fundación ideal. El camino parecía llevar otro derrotero y el último capellán que regentó el templo, el ya citado P. Francisco de Paula Carrillo (exclaustrado, comisario de la V.O.T y comisario provincial entre 1879-1885), dejó la iglesia en manos del arzobispado y no de los frailes franciscanos, cuestión que creemos atribuibles a circunstancias referentes a la jurisdicción y al simbolismo. El capellán que regentó el templo y la V.O.T desde 1885 fue el P. Manuel de Cáceres, el cual acaba enemistado con los seglares franciscanos por una mala administración económica, pero también por el deseo de los seglares de volver a tener un comisario visitador franciscano.

A pesar del interés de los integrantes de la V.O.T, los frailes no pudieron acceder a la posesión del templo, con lo que comenzaron a buscar uno cercano. El elegido fue el del Santo Ángel (actual calle Rioja), antiguo templo carmelita, que seguía conservándose anexo a su convento pero que fue abandonado por los exclaustrados carmelitas debido a la imposibilidad de ampliar el local y pasado el tiempo sin conseguir mejoras para las condiciones de vida ${ }^{103}$. El abandono del local supuso un punto a favor para que fuera incluido en la demolición que se proyectaba para ensanchar dicha calle, pero la actuación de un patrono de la iglesia consiguió detener el envite. Gracias a esta acción la comunidad franciscana logró alojarse en ella en la primavera de 1889, donde comenzó a regentar la Orden Tercera; pero siempre con el pensamiento en recuperar San Buenaventura.

No tardaron en llegar las peticiones al arzobispo de Sevilla y en abril de 1889 se quejaban de las condiciones, apuntando las que ya hicieron los carmelitas: poseemos muy poco local y sin esperanza de poder ensanchar [...] además, perteneciendo esta iglesia y local a los P.P

102 Sebastián GARCIA GARRIDO: La provincia Bética de la Orden de los Frailes Menores, Guadalupe, Real Monasterio de Guadalupe, 1999.

103 S. PUERTA: Los carmelitas descalzos en Andalucía, Sevilla, Zambrano-Tet, 1970, pp. 51-54. 
carmelitas, ellos lo pueden reclamar cuando lo juzguen conveniente ${ }^{104}$. Junto a estas razones materiales nos encontramos otras de distinto tipo: el capellán de San Buenaventura se resistía a irse, los vecinos lo apoyaban, pero la presencia allí de las V.O.T correspondía a la Orden Tercera, al estar restaurada en la ciudad.

La asignación era algo lógico en la mentalidad del arzobispado. Les aseguraba que debían tener paciencia y que mientras otra cosa no se les comunique continúe S.R (Mariano de San José), con los demás religiosos en la Iglesia del Santo Ángel [...] sin ejercer función alguna en la de San Buenaventura ${ }^{105}$. Los frailes, en julio de 1890, viendo que el arzobispado no presionaba tanto como ellos querrían al capellán, se pusieron en contacto con el comisario general por todos los ardides de que se valen estas personas afectas al capellán de San Buenaventura, exponiendo al arzobispo una serie de documentos que justificaban la petición de la naciente provincia:

que la Iglesia de San Buenaventura perteneció a la provincia de Andalucía; la Iglesia siempre ha estado en poder de la Orden hasta que hace cinco años el último comisario provincial fue nombrado canónigo de la catedral de Cádiz; [...] ya mi antecesor pidió la iglesia de San Buenaventura pero la muerte inapropiada de dicho Padre, y la vuelta de los religiosos a Francia impidió tomar posesión; $5^{\circ}$ aunque hay otras iglesias de la Orden en Sevilla quieren San Buenaventura por ser la más céntrica ${ }^{106}$.

Los frailes facilitaron la tarea incluso proponiendo que se cedería la casa adyacente a la sacristía, en poder de un exclaustrado, a la Orden para comenzar a habitar y regentar la Iglesia ${ }^{107}$. No sabemos las razones, ni lo ocurrido en el verano de 1890, pero en noviembre el capellán de la iglesia escribe al arzobispo diciendo que se ha enterado que los frailes han pedido al arzobispo volver a la Iglesia y que, con el fin de facilitar el asunto, renuncia a la capellanía. A pesar de la renuncia, hace constar los grandes sacrificios realizados por él para

104 De Mariano de San José al Arzobispo de Sevilla, (30-IV-1890), AGAS. FA, sec. II, OO.RR Masculinas, leg. 5273, exp. 5.

105 Del arzobispado al Padre Superior de la residencia de religiosos franciscanos del Sto. Ángel (31-V-1890) , AGAS. FA, sec. II, OO.RR Masculinas, leg. 5273, exp. 3.8

106 De Mariano de San José al arzobispo de Sevilla. Desde la Residencia del Santo Ángel (6-IV- 1890) , AGAS. FA, sec. II, OO.RR Masculinas, leg. 5273, exp. 3.9

107 De Mariano de San José al Arzobispo (23-VI-1890), AGAS. FA, sec. II, OO.RR Masculinas, leg. 5273, exp. 3. 10. 
aumentar el culto en la Iglesia. También suplicó que se le nombrase capellán de la Iglesia del Santo Ángel para trasladar las congregaciones fundadas por él en San Buenaventura, junto a los objetos que le pertenecen $^{108}$.

Con el inventariado se produjo el traslado de las cofradías de Nuestra Señora de Lourdes y del Corazón de Jesús y, en consecuencia, de los fieles afiliados a ellas, dándose un cambio: los franciscanos a San Buenaventura y el capellán al Santo Ángel. El 20 de noviembre de 1890 se produjo la entrega solemne del templo a la Orden Franciscana: cincuenta y cinco años después la Orden volvía a tener presencia en la ciudad, sintiéndose heredera de la antigua provincia observante

\section{CONCLUSIONES}

El clero regular asumió el modelo de la Restauración como el menos malo haciéndolo presente mediante una alianza mayoritaria entre el clero y la corona, un apoyo mutuo, que tendrá como fruto el gran esplendor religioso de finales del siglo XIX. En el caso de la familia franciscana, su supervivencia se debía en gran parte a las cesiones estatales (colegios de misiones) que el Concordato de 1851 vino a sistematizar y sentar las bases del futuro renacer. Los colegios de misiones fueron semilleros de vocaciones a los territorios de Ultramar pero también para el entorno del convento, donde los obispos jugaron un gran papel animando a misiones populares y ejercicios espirituales.

Respecto al clero francés expulsado en 1880, escasamente tratado en la historiografía española, tuvieron a España como un refugio transitorio en la espera de tiempos mejores en los que regresar a Francia. En nuestro caso, fue este contingente el que propició la agrupación de los elementos franciscanos, aglutinando frailes españoles y franceses, en una fundación que no buscaban refundar la vida franciscana antigua sino sentar bases para la Orden en Francia. Pero los contextos y azares personales de los religiosos propiciaron que se entroncara con el viejo franciscanismo hispano, concretamente el sevillano, provocando un gran despertar de fundaciones, misiones y vocaciones, que llevaría a que la Provincia Bética Franciscana

108 Carta de Manuel de Cáceres Zozobra al Arzobispo (9-IX-1890), AGAS. FA, sec. II, OO.RR Masculinas, leg. 5273, exp. 3.11. 
restaurada viviera un siglo $X X$ de gran actividad en todos los sentidos. Esta provincia restaurada, aprovechando los vacíos dejados por las antiguas provincias, se expandió por Andalucía Occidental, Islas Canarias y Extremadura, llegando a aglutinar en su interior a todo el viejo franciscanismo de la zona y asumiendo su papel de ser el único referente, en la mayor parte de los territorios, de la Orden Franciscana.

La gran diversidad religiosa franciscana, con gran representaión en la ciudad de Sevilla, llegó a la restauración con miembros de edad muy avanzada, lo que facilitó la disolución de la antigua variedad y la tarea de unificación de toda la familia bajo la denominación "Orden Franciscana de Hermanos Menores" de todo elenco bajo la motivación de León XIII.

La falta de una gran sede propició que los estudios de la Provincia Bética se fueran cambiando de lugar en función del aumento numérico y las necesidades (el Colegio Seráfico de la Bética pasará de Loreto a Fuente del Maestre (Badajoz) con un convento específico para la etapa formativa), donde los colegios seráficos se erguían como una novedad. Una institución que los frailes del Antiguo Régimen no conocieron, pero que con la Restauración, con una sociedad cambiada, se hacían indispensable.

Con todo lo expuesto nos encontramos con varias vías de investigación cuyo estudio reportará un mayor detalle acerca de la vida religiosa: El estudio de la formación en los colegios seráficos y de las misiones que realizaban en busca de individuos aptos para la vida religiosa permitiría también elaborar un perfil sociológico y cultural de la España franciscana de finales del siglo XIX y principios del siglo $X X$, siendo un objeto ampliable hasta los años ochenta del siglo XX. El mismo enfoque habría que darle al papel de los terciarios franciscanos, sus implicaciones sociales y económicas en el territorio donde se circunscriben, permitiéndonos elaborar perfiles de religiosidad y actividades religiosas de los laicos en el mismo período de tiempo. Por otro lado, el estudio de las relaciones institucionales de los elementos locales con los nacionales también nos brindará una radiografía de redes de poder locales, comarcales, provinciales, y nacionales, ayudándonos a definir la voluntad política y social en las fundaciones conventuales de la restauración. Una tarea, hasta ahora tímidamente iniciada, que es imprescindible para todo lo mencionado: descubrir la completa y verdadera realidad de las órdenes religiosas en un tiempo 
en que legalmente se supone que no existían en España, historiar un proceso completo con nuevos métodos y enfoques que nos permitan abrir diversas vías de interpretación de otros elementos relacionados. 
